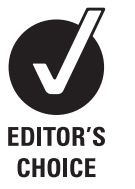
Department of Brain Repair and Rehabilitation, UCL Institute of Neurology and the National Hospital for Neurology and Neurosurgery, Queen Square, London, UK

Correspondence to Dr D J Werring, National Hospital for Neurology and Neurosurgery, Box 6, Queen Square, London WC1N 3BG UK; d.werring@ucl.ac.uk

Received 30 August 2011 Accepted 2 October 2011 Published Online First 5 November 2011

REVIEW

\title{
Sporadic cerebral amyloid angiopathy revisited: recent insights into pathophysiology and clinical spectrum
}

\author{
Andreas Charidimou, Qiang Gang, David J Werring
}

\section{ABSTRACT}

Sporadic cerebral amyloid angiopathy (CAA) is a common age related cerebral small vessel disease, characterised by progressive deposition of amyloid- $\beta(A \beta)$ in the wall of small to medium sized arteries, arterioles and capillaries of the cerebral cortex and overlying leptomeninges. Previously considered to be a rare neurological curiosity, CAA is now recognised as an important cause of spontaneous intracerebral haemorrhage and cognitive impairment in the elderly, two fundamental challenges in the field of cerebrovascular disease. Our understanding of the pathophysiology and clinical manifestations of CAA continues to evolve rapidly, with the use of transgenic mouse models and advanced structural and/or molecular neuroimaging techniques. Yet, despite remarkable recent interest, CAA remains under-recognised by neurologists and stroke physicians. In this review, a fresh look at key developments in understanding the complex pathophysiology, important clinical and radiological features, diagnostic approaches and prospects for rational therapies for this enigmatic small vessel disorder is provided.

\section{INTRODUCTION}

Sporadic cerebral amyloid angiopathy (CAA) is a common small vessel disease of the brain, characterised by the progressive deposition of amyloid$\beta$ (A $\beta$ ) protein in the walls of small to medium sized arteries (up to about $2 \mathrm{~mm}$ in diameter ${ }^{1}$ ), arterioles and capillaries in the cerebral cortex and overlying leptomeninges. ${ }^{2} 3$ CAA can also affect cerebellar vessels but only rarely those in the brainstem or basal ganglia. Although known to pathologists for over a century, ${ }^{4}$ CAA was not linked to clinical disease until as late as the 1960s when it was suggested to be a rare cause of intracerebral haemorrhage $(\mathrm{ICH}) .^{6-8}$ In recent years, CAA has been 'rediscovered' as a common and important cause of spontaneous ICH, which remains the most devastating form of stroke, with a death rate approaching $50 \%$ in contrast with improved outcomes from ischaemic stroke. ${ }^{9}{ }^{10}$ An increased understanding of CAA thus holds promise for improved prevention and treatment of $\mathrm{ICH}$.

The growing interest in CAA is at least partly thanks to two fields of research, which have been important in defining the expanding clinicalradiological phenotype and the underlying pathophysiology of the disease: (1) neuroimaging, which now allows an unprecedented ability to investigate CAA dynamics in vivo using MRI to reveal complex patterns of cerebral bleeding (including lobar microbleeds ${ }^{11}$ ) and ischaemia, and an increasing repertoire of specific amyloid binding ligands ${ }^{3} 12-16$; and (2) transgenic mouse studies, which have allowed the experimental alteration of amyloid peptide expression and molecular structure, providing significant mechanistic insights. Despite these advances, CAA remains under-recognised by neurologists and stroke physicians, making a fresh look especially timely. In this review (see box 1 for search strategy), we provide a comprehensive update, emphasising the widening spectrum of CAA clinical presentations and neuroimaging features, including diagnostic approaches to reliably identify the disease in vivo. Finally, we discuss improved prospects for rational preventive or disease modifying therapies for this common and devastating microangiopathic disorder.

\section{EPIDEMIOLOGY AND RISK FACTORS}

Pathologically defined CAA is common in the elderly. ${ }^{17-20}$ Population based autopsy studies indicate a CAA prevalence of $20-40 \%$ in nondemented and $50-60 \%$ in demented elderly populations (figure 1). ${ }^{19}{ }^{21-24}$ Furthermore, CAA pathology may be severe in older individuals (figure 1): in the Honolulu-Asia Ageing Autopsy Study, severe CAA was found in $43 \%$ of demented and $24 \%$ of non-demented elderly individuals (mean age at death 85 years). ${ }^{23}$ In Alzheimer's disease (AD), CAA is almost invariable being found at autopsy in more than $90 \%$ of cases. ${ }^{17} 25$ However, most of these patients have mild CAA; severe CAA is found in about $25 \%$ of $\mathrm{AD}$ brains. $^{26}$

Advancing age is the strongest known clinical risk factor for developing CAA. ${ }^{2}$ In a community based sample of 100 individuals, the prevalence of cortical vascular $A \beta$ deposition progressively increased from the seventh to the ninth decades, ${ }^{27}$ a pattern also observed in 784 consecutive autopsies, corrected for over-representation of $\mathrm{AD}^{28}$ Moreover, patients with CAA related ICH (suggesting advanced disease) in large autopsy series were all older than 60 years (and most over 70 years of age). ${ }^{7} 2930$ Sporadic CAA is seldom reported before the sixth decade of life; occasional patients presenting in their 50 s have been described. ${ }^{31}$

In contrast with hypertensive arteriopathy-the other main form of small vessel disease and cause of $\mathrm{ICH}^{32}$ - the risk of CAA is not accounted for by conventional cardiovascular risk factors other than age. ${ }^{2}$ Hypertension is not considered a risk factor 


\section{Box 1 Search strategy and selection criteria}

References were identified through PubMed with the search terms: 'cerebral amyloid angiopathy'; 'microbleed(s) or microh(a) emorrhage(s) and cerebral amyloid angiopathy'; 'intracerebral h(a)emorrhage'; and 'vascular cognitive impairment' between January 1970 and August 2011. The references from identified articles and the authors' own files were also searched for relevant publications. Only papers published in English were reviewed. The final reference list was chosen on the basis of relevance to the topics covered in this article.

for developing CAA but may increase the risk of CAA related ICH. Vinters ${ }^{2}$-in a clinicopathological series of 107 pathologically proven CAA cases-found the prevalence of hypertension to be around $32 \%$, similar to community dwelling elderly populations, ${ }^{33}$ while another pathological study reported that CAA patients with ICH were more frequently hypertensive $(50 \%)$ than those without ICH $(23 \%)$, suggesting that hypertension may contribute to CAA related cerebral bleeding. ${ }^{34}$ In a recent multicentre cohort of patients with spontaneous ICH, we found that the prevalence of hypertension in CAA related ICH was $62 \%$-significantly less than in non-CAA related ICH $(85 \%) .{ }^{35}$ Whether hypertension in association with CAA confers a greater risk for ICH compared with CAA alone is an important clinical question. ${ }^{36-38}$ Evidence from the PROGRESS trial of blood pressure lowering after stroke showed that a mean blood pressure reduction of $9 / 4 \mathrm{~mm} \mathrm{Hg}$ reduced the risk of future CAA related ICH by about $77 \%$, supporting an important causal role for hypertension. ${ }^{38}$

Apolipoprotein E (ApoE) alleles are the only known genetic risk factors for sporadic CAA. ${ }^{39} \mathrm{ApoE}$ is a protein with crucial roles in lipoprotein complexes, which regulate lipid metabolism by binding to cell surface receptors and proteins associated with lipid transfer and lipolysis. ${ }^{39}$ There are three major polymorphisms in the ApoE gene-namely, $\varepsilon 4, \varepsilon 2$ and $\varepsilon 3$ - resulting in a single amino acid change ${ }^{40}$ which dramatically alters the

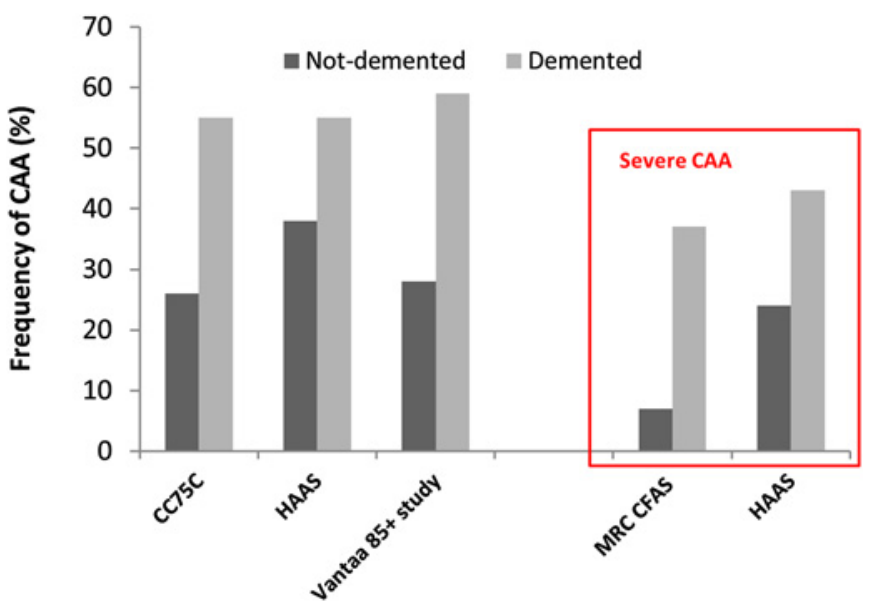

Figure 1 The frequency of cerebral amyloid angiopathy (CAA) in demented and non-demented elderly individuals in population based clinicopathological studies. Note the increased prevalence of CAA, even if only severe pathology is taken into account. CC75C, Cambridge City over 75 Cohort $^{21}$; HAAS, Honolulu-Asia Ageing Study ${ }^{23}$; Vantaa $85+$ study $^{24}$; MRC-CFAS, MRC Cognitive Function and Ageing Study. ${ }^{22}$ functional properties of ApoE isoforms. ${ }^{41}$ These alleles have a strong dose dependent effect on the risk of developing CAA and its clinical severity. Thus ApoE $\varepsilon 4$ in both postmortem and clinical series increases the risk of sporadic CAA related lobar $\mathrm{ICH}$; moreover, the number of $\varepsilon 4$ alleles relates to clinical severity. ${ }^{39}{ }^{42-44}$ Individuals carrying the ApoE 82 allele also have an increased risk of CAA related lobar ICH. ${ }^{44}{ }^{45}$ Both of these risk alleles are also associated with a younger age of first $\mathrm{ICH}^{46}$ greater likelihood of haematoma expansion, poorer clinical outcome $e^{47} 48$ and a higher risk of recurrence. ${ }^{49}$ Furthermore, the two allelic variants interact: patients with both ApoE $\varepsilon 2$ and $\varepsilon 4$ alleles have the earliest disease onset and highest risk of early ICH recurrence. ${ }^{49}{ }^{50}$ The $\varepsilon 2$ and $\varepsilon 4$ alleles might promote CAA related haemorrhage through distinct mechanisms: $\varepsilon 4$ by promoting $A \beta$ deposition and $\varepsilon 2$ by inducing structural changes in amyloid laden vessels, making them prone to rupture. $^{47} 48$ 50-52 Other as yet unidentified genetic polymorphisms relating to amyloid metabolic pathways (figure 2A) may also play a role in sporadic CAA, (eg, presenilin-1, neprilysin and transforming growth factor $\beta-1),{ }^{57-59}$ and are a topic of ongoing investigation.

\section{NEUROPATHOLOGY}

Morphological characteristics, natural history and severity grading

CAA primarily involves neocortical and leptomeningeal arterioles, to a lesser extent capillaries and, very rarely, venules. ${ }^{3}$ In contrast with amyloid plaques found in $\mathrm{AD}$-which are predominantly composed of the 42 amino acid residue fragment $\left(\mathrm{A} \beta_{42}\right)$-the vascular amyloid in CAA is mostly composed of the more soluble, 40 amino acid fragment $\left(A \beta_{40}\right)$, suggesting different pathophysiological mechanisms for pathological deposition (see below) ${ }^{60-63}$ Cerebral vessels with moderate to severe CAA show an acellular wall thickening with a strongly eosinophilic smudgy appearance on haematoxylin-eosin stained sections. ${ }^{64}$ Congo red staining, under polarised light, reveals amyloid deposits as 'apple green' birefringence (hence the term congophilic angiopathy) ${ }^{2}{ }^{6}$ although immunological stains for $A \beta$ are highly specific and now widely used (figure 3 ). The development of CAA is progressive, with $A \beta$ first appearing in the abluminal aspect of the tunica media, surrounding smooth muscle cells, and in the adventitia (figure 3$)^{2}{ }^{2}$ At the initial stage, the vessel wall structure is intact, but as the disease progresses, there is pan-mural amyloid accumulation and loss of smooth muscle cells. ${ }^{3}$ In severe CAA, detachment and delamination of the outer part of the tunica media result in the so-called 'double barrel' appearance (figure 3$)^{3}$; fibrinoid necrosis and microaneurysm formation also occur in advanced disease. There may also be microbleeding with perivascular deposition of erythrocytes and blood breakdown products. ${ }^{64}$ Endothelial cells are usually preserved even in vessels severely affected by CAA. ${ }^{66}$ Occasionally $A \beta$ is deposited in the surrounding brain parenchyma immediately adjacent to an affected vessel (sometimes called 'dyshoric CAA').

CAA is also associated with cerebral ischaemic damage, ${ }^{17} 266768$ including cortical microinfarcts, ${ }^{69}$ and white matter pathology (demyelination and gliosis). ${ }^{817} 62$ Microinfarcts are predominantly lobar (cortical-subcortical), usually in patients with severe CAA. One possible mechanism for these ischaemic lesions is occlusion or reduced perfusion in amyloid laden cortical vessels affected by CAA.

The changes described above provide the basis of neuropathological scoring systems for CAA, ${ }^{34} 670$ each with strengths and limitations. ${ }^{71}$ No standardised consensus neuropathological criteria for rating CAA are available ${ }^{72}$ but are desirable to allow 
Figure 2 (A) Amyloid- $\beta(A \beta)$ production, elimination and deposition in cerebral amyloid angiopathy (CAA). Converging evidence indicates that the major source of $A \beta$ is neuronal. It is generated by sequential cleavage of amyloid precursor protein (APP) by $\beta$ - and $\gamma$-secretases, in proportion to neuronal activity. $A \beta$ is eliminated from the brain by four major pathways: (a) proteolytic degradation by endopeptidases (such as neprilysin and insulin degrading enzyme (IDE)); (b) receptor mediated clearance by cells in the brain parenchyma (microglia, astrocytes and to a lesser extent neurones); (c) active transport into the blood through the blood-brain barrier (BBB); (d) elimination along the perivascular pathways by which interstitial fluid drains from the brain. ${ }^{53} 54$ Specialised carriers (eg, ApoE) and/or receptor transport mechanisms (eg, the low density lipoprotein receptor (LDLR) and LDLR related protein (LRP1)) are involved in all major cellular clearance pathways. Vascular deposition is facilitated by factors that increase the $A \beta_{40}: A \beta_{42}$ ratio (while increased $A \beta_{42}$ leads to oligomerisation and amyloid plaques) and impede perivascular passage. As the clearance mechanisms fail with age, $A \beta$ is increasingly entrapped from the perivascular drainage pathways into the basement membranes of capillaries and arterioles of the brain leading to CAA. ${ }^{556} \mathrm{ApoE}$ alleles have a differential effect on different molecular and cellular processes of $A \beta$ production, elimination and deposition in a way that they either increase or decrease the risk of developing CAA. (B) The roles of different $A p o E$ alleles in various pathways in the brain which might contribute in the pathogenesis and pathogenicity of CAA.
A

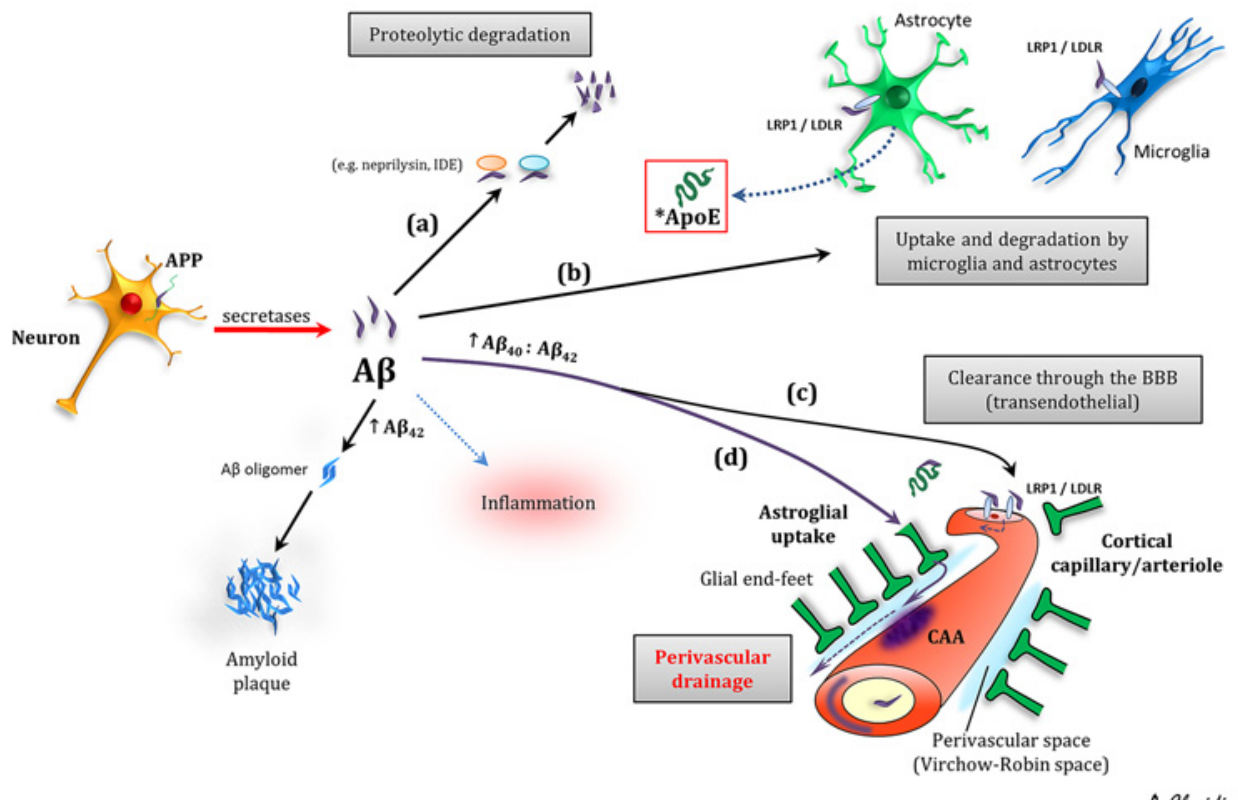

B

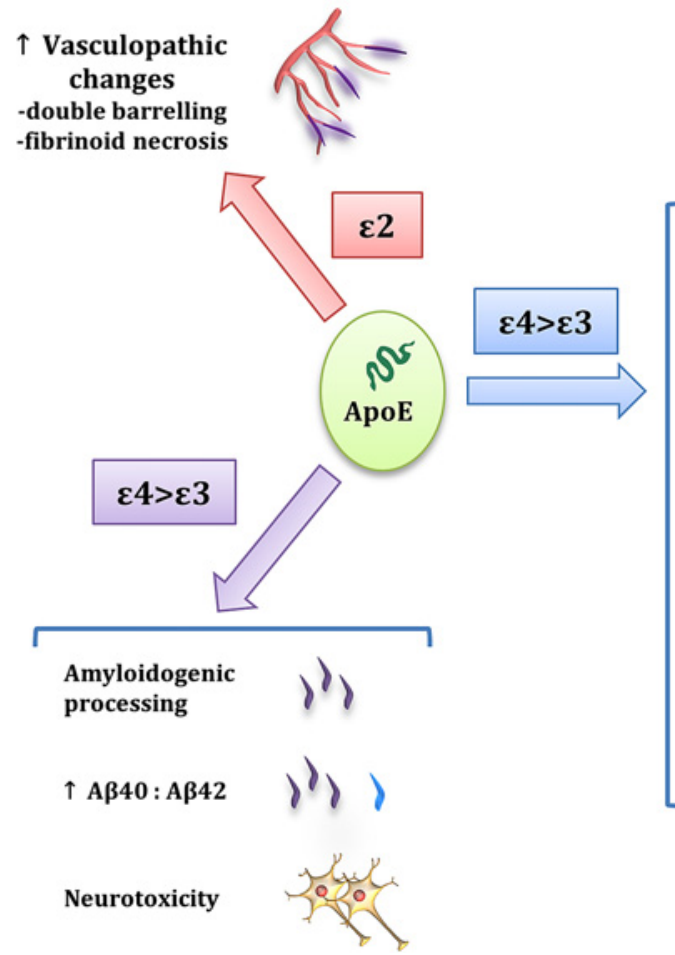

CAA type $2 .^{73}$ CAA type 1 appears to be more closely associated with parenchymal amyloid deposition in $\mathrm{AD} .^{74}$

A more detailed discussion of CAA severity grading can be four in a recent review by Attems and colleagues. ${ }^{3}$

Pathological subtypes of sporadic cerebral amyloid angiopathy At least two distinct pathological subtypes of CAA have been described: CAA type 1 , characterised by $A \beta$ in cortical capillaries (with or without involvement of other vessels) ${ }^{3}$; and CAA type 2 , where $A \beta$ deposits are restricted to leptomeningeal and cortical arteries, arterioles and, rarely, veins. ${ }^{73} \mathrm{~A} \beta$ deposition in the wall of capillaries (capillary CAA) may cause luminal obstruction in the most severe stages. ${ }^{1}$ The Apo E $\varepsilon 4$ allele is most strongly associated with CAA type 1 while Apo E $\varepsilon 2$ is more associated with

\section{Topographical distribution}

Sporadic CAA favours posterior cortical regions; the occipital lobe is most frequently affected, followed by the frontal, temporal and parietal lobes. ${ }^{2} 3$ The occipital lobe is also most severely affected. ${ }^{75} 76$ The cerebellum can be affected in advanced stages while the basal ganglia, thalami, white matter and brainstem are typically spared. ${ }^{71}$ The distribution of CAA pathology shows a characteristic patchy pattern, ${ }^{2}$ so that foci of vessels severely affected by CAA may be adjacent to other with mild or absent $A \beta$ deposition. ${ }^{2}{ }^{3}$ The practical 
Figure 3 Histopathological features of cerebral amyloid angiopathy (CAA).

(A1-A3) Morphological changes of the vessel walls of leptomeningeal arterioles, as revealed by haematoxylin-eosin staining. In mild and moderate CAA, only minimal structural changes can be detected: in (A2) the arrowhead points to amyloid deposition in the vessel wall. However, in advanced CAA, there are significant structural alterations, the most extreme of which is double barrelling (detachment and delamination of the outer part of the tunica media; bracket in (A3)). (B1-B3) A similar pathological range of CAA related changes in leptomeningeal arterioles using immunohistochemical detection of $A \beta$. In mild CAA (B1), there is patchy deposition of amyloid in the vessels wall. Moderate CAA shows more dense amyloid deposition which spans the entire vessel wall (B2) while severe CAA shows double balled vessels and endothelial involvement (B3). (C1-C3) Pathological findings of CAA in cortical arterioles. C2 shows moderate CAA with pan-mural deposition of $A \beta$ along with $A \beta$ deposition in the surrounding brain parenchyma (arrowhead). In (C3), a double barrel vessel can be seen although this is less common compared with leptomeningeal vessels.
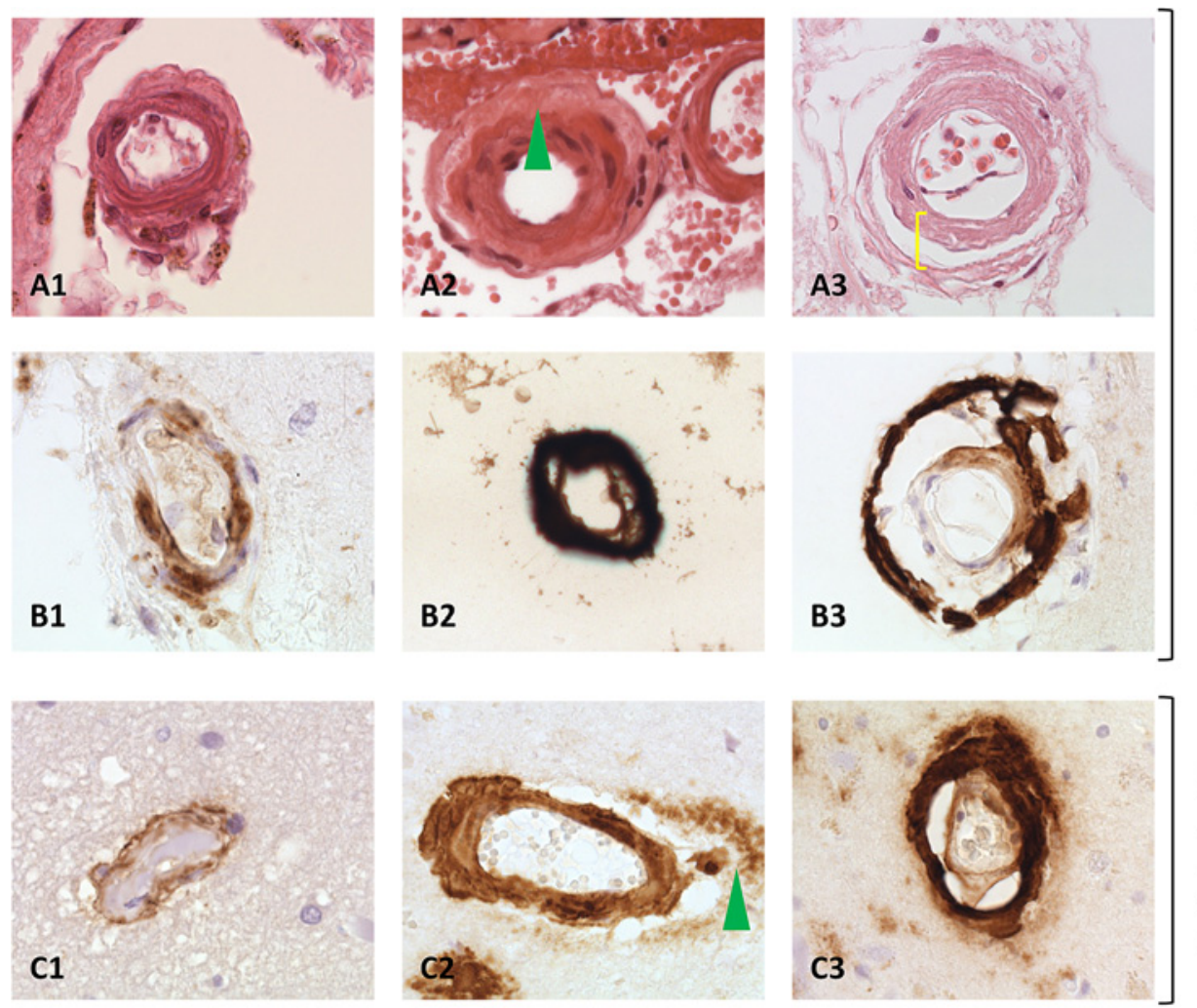

Moderate

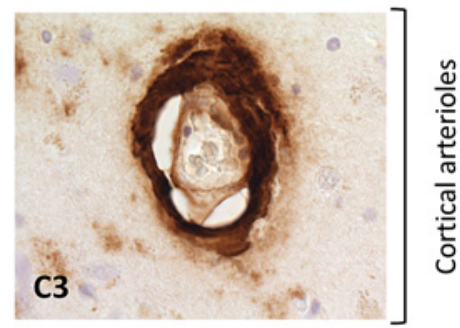

Mild consequence of this is that cerebral biopsy may miss patchy CAA pathology.

\section{PATHOPHYSIOLOGICAL PATHWAYS}

Amyloid- $\beta$ production, clearance and accumulation

$A \beta$ is generated by sequential cleavage of amyloid precursor protein (APP) by $\beta$ - and $\gamma$-secretases. Mutations in the gene encoding the APP account for some rare (usually autosomal dominant) forms of CAA, including CAA Dutch type. ${ }^{77}$ Familial non- $A \beta$ forms of CAA include familial British dementia, ${ }^{78} 79$ familial Danish dementia ${ }^{80}$ and Icelandic cystatin C mutation. ${ }^{81}$ In general, hereditary forms of CAA have an earlier onset and more severe clinical manifestations than sporadic CAA. ${ }^{64} 82$ Although exceptionally rare, familial CAAs have provided significant insights on how mutations in the coding region of the APP contribute to CAA pathogenesis: for example, the Iowa, Dutch, Italian and Arctic mutations render $A \beta$ highly toxic to vessel wall components ${ }^{83-85}$ and more resistant to proteolytic degradation ${ }^{86}$ or clearance from the brain (figure 2)..$^{55}$

Factors that initiate or promote $A \beta$ peptide deposition in the much more common sporadic CAA are not as well understood. Nevertheless, transgenic mouse models of cerebral amyloid deposition ${ }^{3}$ have provided the following insights (figure 2): (1) the major source of human $A \beta$ is neuronal ${ }^{87} 88$; (2) an increased ratio of $A \beta_{40}: A \beta_{42}$ in the brain results in a shift from brain parenchyma to the vasculature (perhaps by increasing the solubility of $A \beta$ and thus its diffusion into the vessel wall ${ }^{53}$; and (3) vascular $A \beta$ deposition largely results from impaired clearance of $A \beta$ (rather than overproduction), especially along perivascular drainage pathways. ${ }^{3} 5489$ Impairment of peri- vascular drainage pathways has emerged as a key mechanism in sporadic $\mathrm{CAA}^{3} 569^{0}$ : these efflux channels may be conceptualised as a cerebral 'lymphatic system', allowing interstitial fluid and solutes to drain out of the brain along basement membranes in the capillary walls, and between smooth muscle cells in the tunica media of small arteries (in the opposite direction to arterial blood flow) (figure 2) ${ }^{91}$ This transport system is thought to be driven by pulsations of the blood vessel wall..${ }^{91}$ As this and other clearance mechanisms fail in the ageing brain, or under other pathological conditions, $A \beta$ is increasingly trapped and deposited in the walls of small arteries (figure 2) ${ }^{91}$ Evidence is emerging that cerebrovascular disease may impede the drainage along the perivascular pathways, contributing to CAA pathogenesis. ${ }^{90} 93$

It has been suggested that $A \beta$ deposition could further impair/ block the perivascular drainage, leading to dilation of perivascular spaces (also known as Virchow-Robin spaces), not only within lobar regions but also in the underlying white matter that itself is unaffected by CAA. ${ }^{94} 95$ These enlarged perivascular spaces can reach several millimetres in diameter and may be visible on appropriate brain imaging; this requires further investigation as a potential useful neuroimaging marker of CAA. 9596

As we have seen, ApoE is a strong genetic risk factor for CAA, an effect mediated by its important role in $A \beta$ metabolism, aggregation and clearance (figure $2 \mathrm{~B}$ ). ${ }^{39} 5489 \mathrm{ApoE} \varepsilon 4$ increases the $A \beta_{40}: A \beta_{42}$ ratio, shifting amyloid deposition to the vessels instead of brain parenchyma, ${ }^{53}$ and may reduce the efficiency of efflux of $\mathrm{A} \beta$ along perivascular channels, ${ }^{3}{ }^{97}$ influencing CAA risk and age of onset. ${ }^{39} 98$ ApoE genotype may also interact with 
other small vessel disease changes: hypertensive arteriopathy, which leads to stiffening of the vessel wall, may reduce the pulsatile driving movements required for efficient perivascular drainage and thus contribute to the risk of CAA. ${ }^{3}$

\section{From amyloid- $\beta$ deposition to cerebral amyloid angiopathy pathogenesis}

A $\beta$ deposition has complex effects on vascular structure and function which can result in brain injury. ${ }^{32} 99$ Important morphological changes include: loss of smooth muscle cells ${ }^{100}$; vessel wall thickening and lumen restriction ${ }^{67}$; endothelial dysfunction; and a loss of compliance leading to brittle, fragile vessels prone to microaneurysm formation and leakage. ${ }^{3}$ Acute trigger factors-for example, sudden increases in blood pressure-or minor trauma (regularly encountered in clinical practice but not to our knowledge formally studied) may cause the rupture of these abnormally weak, amyloid laden vessels. A $\beta$ deposition may also impair local regulation of cerebral blood flow, ${ }^{99}$ neurovascular unit function ${ }^{101}$ and general homeostatic mechanisms in the ageing brain. ${ }^{35}$ Other effects of vascular $A \beta$, including blood-brain barrier disruption and active inflammation, could also contribute. ${ }^{399}$ Moreover, even without vascular deposition, soluble $A \beta$ can cause abnormal vascular reactivity ${ }^{99}$ and induce the activation of inflammatory mediators, including matrix metalloproteinase-9 and $-2 .^{3} 102103$

\section{THE EXPANDING CLINICAL SPECTRUM OF SPORADIC CEREBRAL AMYLOID ANGIOPATHY}

There are at least four important clinical presentations associated with CAA:

- Symptomatic intracerebral haemorrhage

- Cognitive impairment and dementia

- Rapidly progressive cognitive and neurological decline

- Transient neurological symptoms

\section{Intracerebral haemorrhage}

Association between cerebral amyloid angiopathy and intracerebral haemorrhage

CAA is most often recognised in life by symptomatic, spontaneous, lobar ICH in elderly patients. The majority of ICHs $(>75 \%)$ in the elderly are classified as spontaneous (sometimes also termed primary or non-traumatic), resulting from rupture of small arteries affected by two main processes: hypertensive arteriopathy or CAA. Hypertensive arteriopathy-characterised by lipohyalinosis and fibrinoid necrosis of small lenticulostriate arterial perforators-is considered an important cause of spontaneous ICH in deep or infratentorial locations (basal ganglia, thalamus and pons). By contrast, CAA related ICHs preferentially affect cortical-subcortical (lobar) regions (especially the occipital and temporal lobes ${ }^{104}$ ), less commonly the cerebellum and rarely deep or brainstem structures, reflecting the distribution of the underlying microangiopathy. ${ }^{2} 3075$ The predilection for the occipital lobes is not well understood but one hypothesis is that greater tortuosity of occipital small arteries impairs perivascular drainage. ${ }^{3}$

Clinicopathological studies suggest that CAA related $\mathrm{ICH}$ accounts for at least 5-20\% of all spontaneous ICH, ${ }^{2} 172634105106$ and that the link is strongest for lobar ICH. However, there are methodological challenges in attributing ICH to CAA: most pathological case control studies did not systematically control for potential confounding risk factors for CAA, including cognitive impairment, ethnicity or age. Furthermore, pathological studies showed differences in the prevalence of ICH only when comparing the presence of low grade CAA versus moderate to high grade CAA, ${ }^{23} 263467$ 107-110 suggesting that mild CAA may not confer such a high risk of ICH. Since many elderly individuals in population based studies have subclinical CAA without haemorrhage, CAA (especially if mild) may not be a sufficient cause of lobar ICH alone, but may interact with other factors-for example, hypertension, neurodegenerative pathology or the use of anticoagulant drugs. ${ }^{23} 263467107-110$

Clinical features of cerebral amyloid angiopathy related intracerebral haemorrhage

CAA related ICHs have some distinct neuroimaging features, which are shown in figure $4^{75} 111$ However, the clinical presentation of CAA related ICH is similar to other forms of lobar ICH (eg, due to tumours or arteriovenous malformations) and varies according to ICH size and location. Patients usually present with an acute stroke syndrome with focal neurological deficits that may be associated with headache, nausea, vomiting, seizures and/or altered level of consciousness (especially large lobar bleeds). ${ }^{10}$ There may also be a history of apparently minor head trauma, which might predispose to $\mathrm{ICH}$ in individuals with CAA. The typical lobar location of haemorrhage more often leads to acute seizures than in deep ICH. A first ever ICH due to CAA may be relatively mild clinically but this is counterbalanced by the high risk of recurrent haemorrhages; indeed, subsequent ICH (which characteristically may cluster over a short period of time (days to weeks)) is often much more severe. ${ }^{112}$ In the longer term, survivors of lobar ICH are at higher risk of recurrence compared with deep $\mathrm{ICH}$, with a rate of about $10 \%$ per year in elderly cohorts. ${ }^{2} 112$ Recurrent haemorrhages are typically lobar, often in the same lobe as the initial CAA related bleed. ${ }^{104}$ Multiple simultaneous lobar haemorrhages are characteristic of CAA related ICH. Recovery from lobar ICH is often poor: negative prognostic factors include older age ${ }^{46}$ and larger haematoma size $e^{113}$; conversely, a small superficial ICH without intraventricular extension is associated with better outcome.

\section{Anticoagulant related haemorrhage}

CAA may be an important risk factor or cause for ICH related to oral anticoagulation use. Over the past decade there has been a fivefold increase in the incidence of anticoagulant related $\mathrm{ICH}$, which now accounts for about $15 \%$ of all $\mathrm{ICH}^{114}$ This trend is probably due to increasing use of warfarin to prevent cardioembolic stroke in elderly patients with atrial fibrillation. Anticoagulant use per se should not cause ICH if cerebral vessels are intact but the presence of CAA, rendering vessels brittle and fragile, is a plausible aggravating factor for such haemorrhage; an otherwise innocuous minor and self-limiting vessel leak (eg, a cerebral microbleed (CMB), see below) could form a life threatening haematoma if the leaking vessel is damaged by advanced CAA. Evidence supporting a link between CAA and anticoagulation related $\mathrm{ICH}$ includes the following observations: first, most such ICH occur with international normalised ratios within the therapeutic range ${ }^{115}$ suggesting that an intrinsic disorder of cerebral small vessels could be important; and second, the ApoE e2 allele is more common in warfarin related ICH than in patients on warfarin without $\mathrm{ICH}$, supporting a role for CAA ${ }^{115}$ Although CAA may underlie a substantial proportion of anticoagulation related haemorrhages, prospective studies with reliable diagnosis of CAA in life (eg, by MRI evidence of lobar $\mathrm{CMBs}$ or molecular imaging) in cohorts of patients treated with anticoagulants are urgently needed to answer this question (one large prospective MRI study is currently underway in the UK: http://www.ucl.ac.uk/cromis-2). 

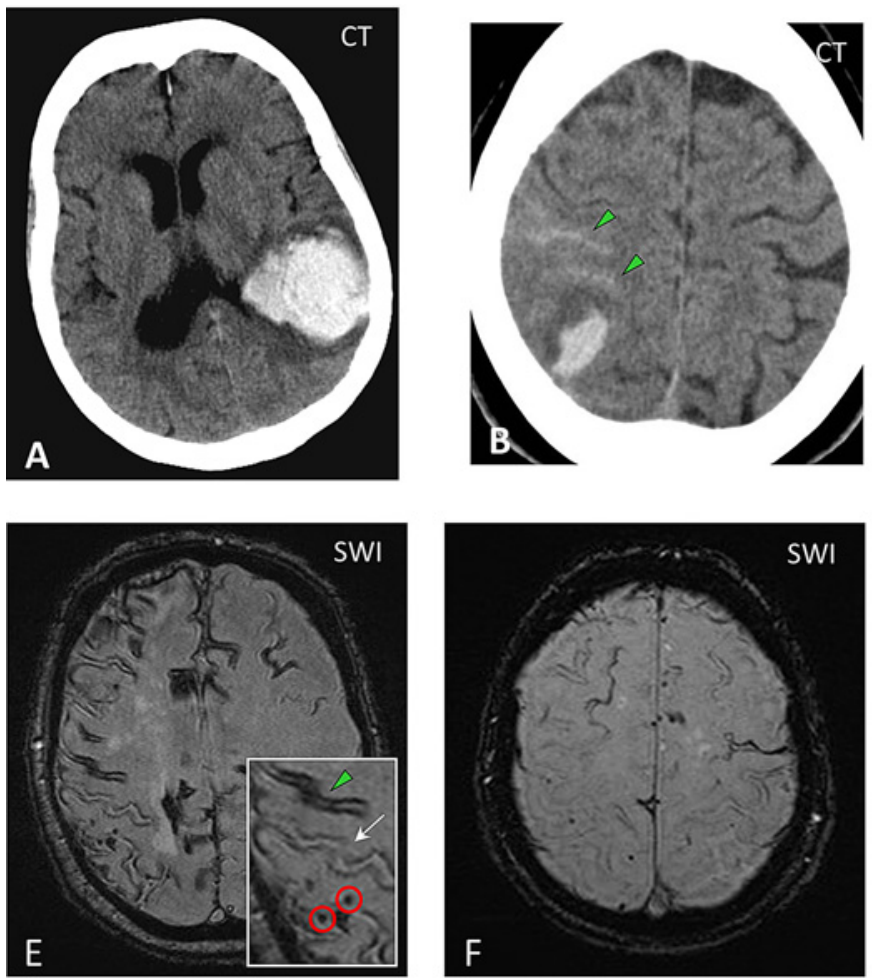
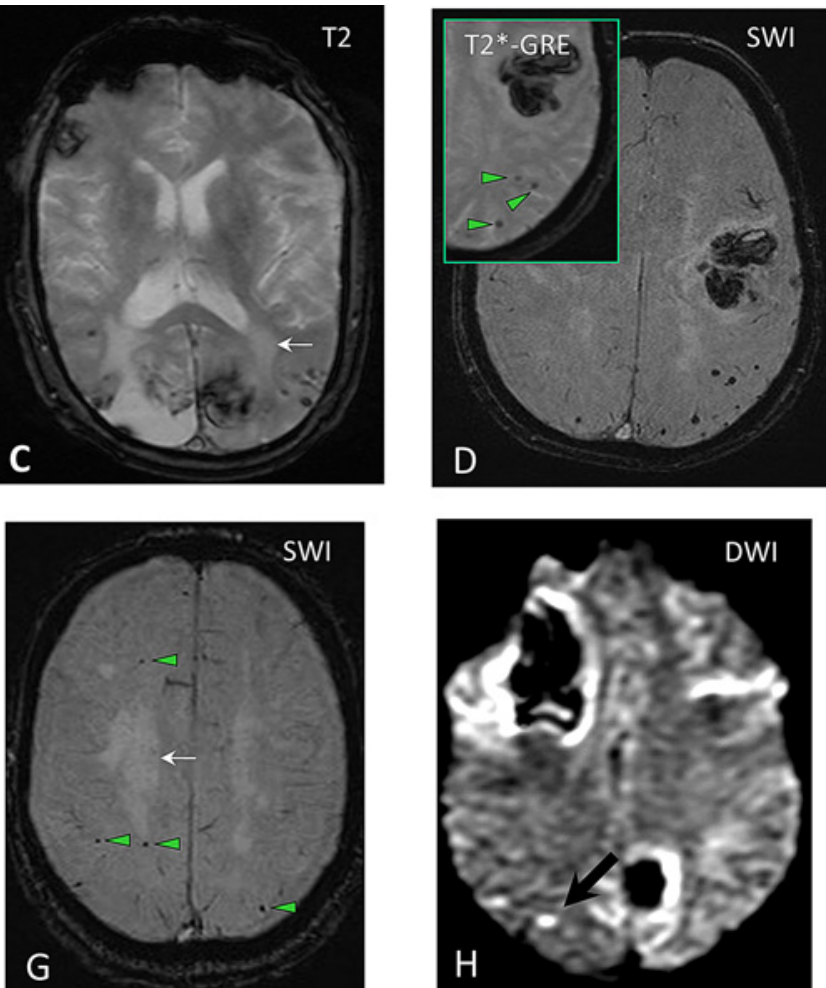

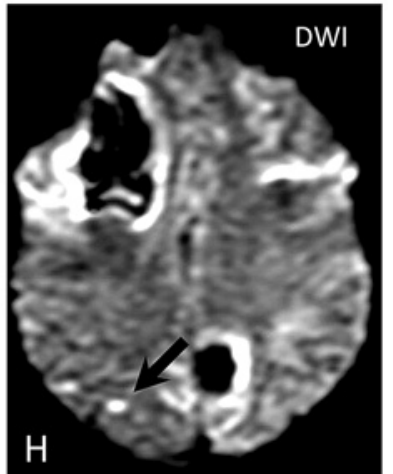

Figure 4 The spectrum of imaging manifestations of sporadic cerebral amyloid angiopathy (CAA). (A) An acute lobar haematoma on CT scan. Some extension of the bleeding in the posterior horn of the left ventricle can be seen. (B) CT scan of a patient with a small posterior cortical haematoma. Acute cortical subarachnoid haemorrhage ( $\mathrm{CSAH}$ ) is evident in two adjacent sulci (arrowheads). (C) A T2 weighted MRI of a patient with probable CAA showing two lobar foci of recent/subacute intracerebral haemorrhage (ICH): in the medial aspect of the left occipital lobe and in the right inferior frontal gyrus. There is also a large old lobar haemorrhage involving the right occipital lobe, some scattered cortical-subcortical cerebral microbleeds (CMBs) in posterior brain regions, as well as confluent white matter hyperintensities in the posterior white matter (leukoaraiosis: arrow). (D) Susceptibility weighted imaging (SWI) and T2* weighted gradient recalled echo (T2*-GRE) (inset) done on the same day in a patient with a lobar haemorrhage. The detection of strictly lobar CMBs (better demonstrated on SWI) is consistent with a diagnosis of probable CAA. (E-F) cSAH (linear hypointensities in the subarachnoid space on T2*-GRE/SWI) and cortical superficial siderosis (hyperintense on T2*-GRE/SWI). The inset in (E) demonstrates the coexistence of cSAH (arrowhead), focal cortical siderosis in an adjacent sulcus (arrow) and some CMBs (circles). Focal cortical siderosis represents the chronic lesion following acute $\mathrm{CSAH}$. (G) SWI in a patient presenting with progressive cognitive impairment led to the detection of multiple strictly lobar microbleeds, characteristic of CAA. Confluent white matter changes (arrow) are also visible. (H) Diffusion weighted imaging (DWI) showing a small acute 'silent' ischaemic lesion in the right parietal lobe (arrow) in a patient with probable CAA.

CAA may also be a risk factor for ICH after thrombolysis: spontaneous CAA related and thrombolysis related haemorrhages share some features, including a predilection of lobar brain regions, multiplicity of haemorrhages, age dependency and an association with dementia and leukoaraiosis. ${ }^{116}$ In one small study, two of five cases of ICH after thrombolysis for acute myocardial infarction had severe CAA identified. ${ }^{117}$

\section{Cognitive impairment and dementia}

There is now increasing evidence that CAA is an important contributor to cognitive impairment ${ }^{72} 118$ although dissecting its independent cognitive impact is confounded by the presence of coexisting $\mathrm{AD}$ and other age related pathologies (eg, hypertensive arteriopathy). Nevertheless, in population based clinical-pathological studies, the prevalence of CAA is consistently higher in demented compared with non-demented patients (figure 1). ${ }^{19}$ In the population based Medical Research CouncilCognitive Function and Ageing Study, CAA was significantly associated with dementia (OR 9.3, 95\% CI 2.7 to 41.0), even after controlling for age and dementia related neuropathologies (eg, neuritic and diffuse plaques). ${ }^{22}$ Similarly, the HonoluluAsia Ageing Autopsy Study revealed a significantly higher prevalence of severe CAA in demented versus non-demented patients (43\% vs $24 \%$ ) (figure 1). ${ }^{23}$ CAA may worsen the severity of cognitive dysfunction in $\mathrm{AD}$ : $\mathrm{CAA}$ together with $\mathrm{AD}$ pathology has been associated with significantly worse cognitive performance during life, compared with $\mathrm{AD}$ alone, even after controlling for age, neurofibrillary tangles and amyloid plaques number, infarctions and ApoE genotype. ${ }^{23}$ There are few studies of the specific pattern of cognitive impairment associated with CAA; a recent autopsy series found that moderate to severe CAA (present in $19 \%$ of the study population) was associated with lower performance in specific cognitive domains, notably perceptual speed and episodic memory, after accounting for $\mathrm{AD}$ pathology and other potential covariates. ${ }^{119}$ The pathophysiological mechanisms by which CAA could cause cognitive impairment have not been well established ${ }^{118}$ but relevant lesions on brain imaging could include cerebral microbleed, ${ }^{120}$ microinfarcts ${ }^{35121}$ and white matter changes. ${ }^{122}$

CAA is thus emerging as a potentially important link between neurodegenerative and cerebrovascular pathology. ${ }^{123}$ Vascular cognitive impairment and $\mathrm{AD}$ are now conceptualised as a continuum ${ }^{118124125}$ with complex interactions and shared risk factors. $^{99} 123$ CAA seems likely to exacerbate the deleterious effect of neurodegenerative pathology on the brain, lowering the threshold for overt dementia. ${ }^{99} 118$ Unravelling the independent contribution of CAA to cognitive function is particularly important as it could lead to new therapeutic strategies. 
Rapidly progressive cognitive and neurological decline: cerebral amyloid angiopathy related inflammation

CAA is clearly a direct cause of cognitive impairment in the uncommon but clinically striking presentation of CAA related inflammation (also termed cerebral amyloid angiitis, amyloid $\beta$ related angiitis and cerebral amyloid inflammatory vasculopathy). ${ }^{126}$ CAA related inflammation typically affects older adults, who present with acute to subacute cognitive decline, headache, behavioural change, seizures and focal neurological deficits. ${ }^{126}$ Typical MRI findings include patchy or confluent, asymmetric T2 weighted or FLAIR white matter hyperintensities (with or without mass effect and leptomeningeal or parenchymal enhancement). ${ }^{126} \mathrm{~T} 2{ }^{*}$ weighted gradient recalled echo (T2*-GRE) or susceptibility weighted imaging (SWI) may reveal previous lobar haemorrhage and/or multiple cortical and subcortical microbleeds. ${ }^{126}$ The major differential diagnoses include infections (in particular progressive multifocal leucoencephalopathy), neurosarcoidosis, immune related conditions (eg, acute disseminated encephalomyelitis) ${ }^{127}$ and malignancies. ${ }^{126}$ Definite diagnosis requires brain and leptomeningeal biopsy showing perivascular inflammation with mononuclear or multinucleated giant cells associated with $A \beta$ laden vessels and/or frank vasculitis. ${ }^{126}$ Although the clinical course of CAA related inflammation is varied, it is important to recognise because it may respond well to immunosuppressive treatment (eg, high dose corticosteroids or cyclophosphamide). ${ }^{126}{ }^{128}$ This distinct syndrome has parallels with that observed in patients with $\mathrm{AD}$ who developed meningoencephalitis after immunisation against human $A \beta$, where postmortem examination revealed inflammation and/or vasculitis associated with CAA. ${ }^{129} 130$

\section{Transient focal neurological episodes}

After ICH, the next most commonly described clinical presentation of sporadic CAA is with transient neurological episodes, ${ }^{131-133}$ sometimes termed 'amyloid spells'. The most common type of attack involves recurrent, stereotyped episodes of 'positive' spreading sensory symptoms (paraesthesias). ${ }^{131} 132$ Although there are a number of small case reports and series, ${ }^{131} 132134135$ no large systematic studies have investigated the prevalence or semiology of these phenomena. At least two other types of transient events have been described: partial motor seizure-like episodes (eg, limb shaking); and visual disturbances (usually positive visual symptoms similar to migrainous auras). Spells are typically brief, almost always less than about $30 \mathrm{~min}$, and usually less than a few minutes. The attacks seem likely to be related to haemorrhagic components of CAA: associated neuroimaging findings reported include CMBs and convexity subarachnoid haemorrhage (cSAH) in the cortical region corresponding to the spell (figure $4 \mathrm{E}$ ). ${ }^{131} 135$ The diagnosis of these CAA related attacks is of clinical relevance as they seem to precede serious symptomatic ICH in some patients; antiplatelet or anticoagulant use following such an attack misdiagnosed as a transient ischaemic attack (TIA) could therefore cause potentially avoidable intracranial bleeding. The underlying mechanisms of CAA transient spells remain unclear but could include seizure-like activity (perhaps related to small areas of bleeding-for example, microbleeding, cSAH or superficial siderosis); a direct effect of amyloid or bleeding on local cortical function; or spreading cortical depression. ${ }^{131}$ The responsiveness of these attacks to antiepileptic drugs as well as their spreading nature in many of the reported cases is in favour of a seizure-like mechanism for their pathophysiology. In a case series by Roth and colleagues, ${ }^{132}$ four out of six patients with these transient attacks responded to anticonvulsants while the other two patients showed improvement after cessation of antiplatelet therapy. Typical TIA-like episodes have also been reported in $\mathrm{CAA}^{133}$ but whether these are genuinely due to ischaemia and should be treated with antithrombotic agents requires further study.

\section{NEUROIMAGING (MRI) CORRELATES OF CEREBRAL AMYLOID ANGIOPATHY}

The important MRI correlates of CAA (figures 4 and 5) include:

- Cerebral microbleeds

- White matter changes (leukoaraiosis)

- Convexity subarachnoid haemorrhage

- Cortical superficial siderosis

- Silent acute ischaemic lesions

\section{Cerebral microbleeds}

The widespread use of T2* weighted MRI sequences in the past decade or so has led to the increasing detection of CMBs: small, well demarcated, hypointense, rounded lesions, not detected on conventional MRI (figure 4D-G). ${ }^{136}$ Histopathological studies show that CMBs correspond to focal accumulations of haemosiderin laded macrophages (a blood breakdown product) adjacent to abnormal small vessels affected by hypertensive angiopathy or CAA. ${ }^{137} 138$ There is increasing evidence that hypertensive vasculopathy is associated with CMBs in deep brain regions (basal ganglia, thalamus and brainstem) whereas CAA is characterised by CMBs in a lobar distribution ${ }^{136} 138$ with a predilection for the parietal lobes. ${ }^{104}$ The Rotterdam scan study $^{139} 140$ showed a strong association between strictly lobar (but not deep) $\mathrm{CMBs}$ and ApoE $\varepsilon 4$, consistent with the well known relation of this allele with $\mathrm{CAA}^{49} \mathrm{~A}$ recent imaging study in clinically probable CAA, using non-invasive amyloid imaging with Pittsburgh Compound $\mathrm{B}(\mathrm{PiB})$, found that CMBs correspond to areas with a high concentration of amyloid. ${ }^{141}$ Moreover, $\mathrm{CMBs}$ correlate with the risk of lobar ICH recurrence, ${ }^{142}$ suggesting an important role in prognosis (as well as diagnosis) in CAA. ${ }^{11}$

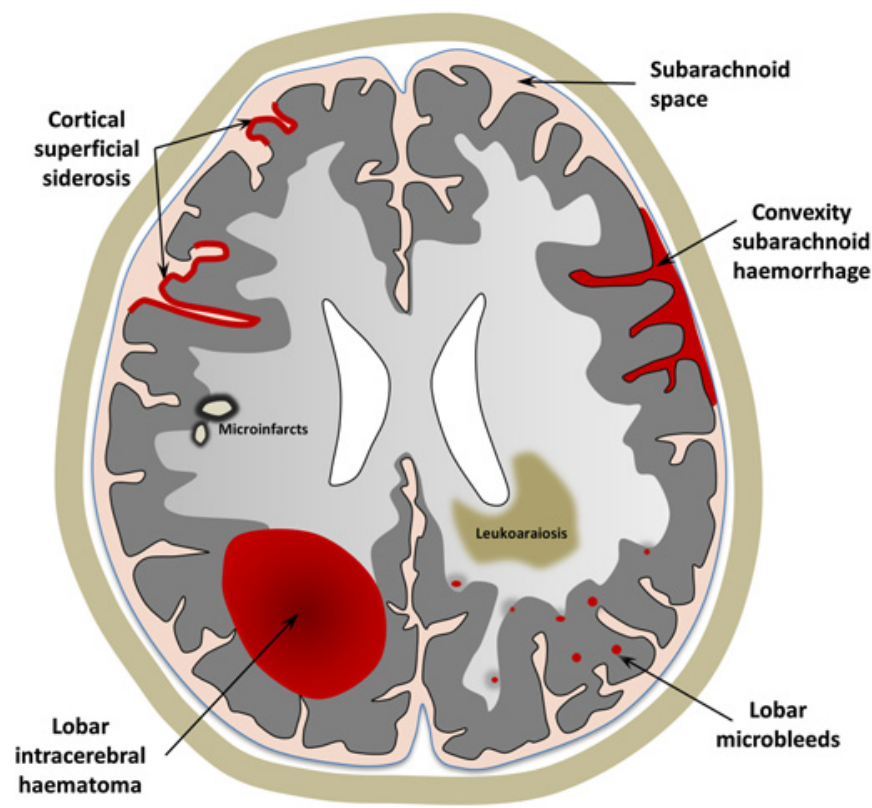

Figure 5 A schematic representation of the spectrum of haemorrhagic and ischaemic manifestations of sporadic cerebral amyloid angiopathy, visible on $\mathrm{MRI}$. 
Recent population based studies have revealed a high percentage of community dwelling elderly people with strictly lobar microbleeds (particularly in the posterior brain regions), suggesting subclinical CAA. ${ }^{139} 140143144$ This may have important implications: if strictly lobar $\mathrm{CMBs}$ are validated as a diagnostic marker of CAA, such asymptomatic individuals could benefit from new therapeutic agents to reduce the progression of the disease.

Neuroimaging studies have revealed lobar $\mathrm{CMBs}$ in more than $20 \%$ of patients with $\mathrm{AD},{ }^{145}$ probably reflecting advanced CAA (in keeping with neuropathological findings). Patients with autosomal dominant forms of familial $\mathrm{AD}$ (who have a younger age at symptom onset), also seem to have a prevalence of lobar $\mathrm{CMBs}$ similar to sporadic $\mathrm{AD}^{146}$ - a striking recent observation since these patients are much more likely to have 'pure' neurodegenerative $\mathrm{AD}$ without coexisting sporadic small vessel disease. It has been suggested that the presence of multiple lobar $\mathrm{CMBs}$ in patients with $\mathrm{AD}$ may identify a specific subgroup of patients with a different clinical phenotype with therapeutic implications which need to be explored in future studies. ${ }^{145}$

\section{Leukoaraiosis}

Leukoaraiosis is a radiological term which describes imaging changes (often confluent) in deep cerebral white matter. Leukoaraiosis appears as low attenuation on CT scans or hyperintensity on T2 weighted or FLAIR MRI, typically sparing subcortical U fibres (figure 4C). ${ }^{147}$ Pathological substrates include demyelination, axon loss and mild gliosis. The pathogenesis of leukoaraiosis in CAA probably involves chronic hypoperfusion of the vulnerable periventricular white matter and disruption of the blood-brain barrier due to amyloid in the overlying cortical small vessels. ${ }^{32} 95148$ Another possible mechanism of leukoaraiosis in CAA is as a result of the accumulation of silent ischaemic lesions (microinfarcts). ${ }^{12} 35149$ Indeed, leukoaraiosis is very common in CAA, preferentially involving posterior regions, ${ }^{150}$ although some studies suggest no major difference in the topography of leukoaraiosis in CAA compared with hypertensive arteriopathy. ${ }^{122}{ }^{150}$ A recent investigation suggested that subjects with CAA related lobar ICH have a higher prevalence of occipital dominant leukoaraiosis compared with normal elderly controls $^{151}$; this interesting finding requires further clinical attention and investigation. Leukoaraiosis may be an important contributor to overall disease burden, especially progressive cognitive impairment, ${ }^{152}$ given its tendency to accumulate over time. ${ }^{153}$ A recent study found that leukoaraiosis volume was greater in patients with CAA and hypertension than those without, suggesting that strict control of hypertension might reduce leukoaraiosis related disability in CAA. ${ }^{152}$

\section{Convexity subarachnoid haemorrhage and cortical superficial siderosis}

Atraumatic cSAH and superficial siderosis are recently recognised imaging correlates of sporadic $\mathrm{CAA}^{154}$ which seem to be quite characteristic of the disorder (figure $4 \mathrm{E}, \mathrm{F}$ ). cSAH is localised bleeding, usually in up to several adjacent sulci, without other subarachnoid bleeding at the base of the brain in the pattern typically associated with saccular aneurysm rupture. ${ }^{155}$ Although rare in isolation, in CAA, cSAH often results from lobar ICH extending to the cortical surface. ${ }^{134} 154156$ The largest cohort of patients with isolated cSAH published $(n=29)$ found that CAA was a frequent apparent cause in patients over 60 years old. ${ }^{155157}$ A recent retrospective analysis of consecutive patients admitted to a tertiary stroke unit with cSAH suggested that CAA could be a common cause in the elderly, with a characteristic clinical presentation of single or recurrent transient focal neurological attacks. ${ }^{135}$ Another recent study of a cohort of patients presenting with $\mathrm{cSAH}$ reported similar findings. ${ }^{158}$

Cortical superficial siderosis describes haemosiderin deposition in the superficial layers of the cerebral cortex (figure 5), and may follow repeated episodes of bleeding in the subarachnoid space. ${ }^{154}$ On T2*-GRE MRI sequences, cortical superficial siderosis shows a characteristic 'gyriform' pattern of hypointense signal (figure 5E,F). ${ }^{154}$ Linn et al have recently detected cortical superficial siderosis in $47.4 \%(n=38)$ of patients with a clinical diagnosis of CAA compared with no controls (mean age 54 years), suggesting that it might be helpful for the clinical diagnosis of CAA (see below). ${ }^{159}$ Compared with the well known syndrome of CNS superficial siderosis, which typically affects the brainstem and posterior fossa (associated with cerebellar and brainstem signs), CAA related siderosis has a predilection for the cerebral convexity ${ }^{160}$ and may be associated with transient neurological manifestations. ${ }^{132}$

\section{Silent acute ischaemic lesions on diffusion weighted imaging} Neuropathological evidence of asymptomatic ischaemic infarction is an established finding in the brains of patients with advanced CAA. ${ }^{8}{ }^{67-69}$ Recent studies using magnetic resonance diffusion weighted imaging-which is extremely sensitive to even small areas of acute ischaemia-have shed light on the dynamics of this phenomenon in vivo (figure $4 \mathrm{H}$ ). A case report $^{13}$ and a recent case control study ${ }^{12}$ found a high prevalence of diffusion weighted imaging positive lesions in patients with advanced CAA. These lesions were associated with CMB burden, suggesting shared pathophysiological pathways. ${ }^{161}$ Gregoire et al recently established that acute, subclinical ischaemic brain lesions are frequent after recent acute $\mathrm{ICH}$, and are three times more common in CAA related $\mathrm{ICH}$ than other spontaneous bleeds ${ }^{35}$; the lesions were associated with the severity of leukoaraiosis and lobar $\mathrm{CMBs}$, suggesting that they were due to a CAA related occlusive arteriopathy. ${ }^{35}$ These data suggest a dynamic interplay between the haemorrhagic ('microbleeding') and ischaemic ('microinfarction') components in $\mathrm{CAA}^{161}$ although the therapeutic implications and prognostic significance of these findings require further study.

\section{MOLECULAR IMAGING OF VASCULAR AMYLOID IN VIVO}

MRI indirectly detects the consequences of CAA (eg, CMBs, $\mathrm{cSAH}$ and siderosis) rather than vascular amyloid itself. Consequently, a large proportion of 'silent' CAA may be as yet undetectable. Positron emission tomography methods allow the in vivo imaging of amyloid in the brain, using several radioligands, of which the most widely studied is ${ }^{11} \mathrm{C} \mathrm{PiB} .{ }^{162}$ Ly et al demonstrated that CAA subjects had increased global PiB uptake relative to a healthy elderly control group, and found an occipital predominance of $\mathrm{PiB}$ retention in CAA compared with $\mathrm{AD} .{ }^{16} \mathrm{PiB}$ positron emission tomography might therefore ultimately detect CAA in vivo, even before it causes symptomatic ICH or the known radiological sequelae, including CMBs. ${ }^{14} 15141163$

\section{DIAGNOSTIC APPROACH TO CEREBRAL AMYLOID ANGIOPATHY: THE CRITICAL ROLE OF NEUROIMAGING}

A common clinical scenario where sporadic CAA should be suspected is in elderly patients presenting with lobar ICH. The most commonly used criteria for CAA diagnosis are the Boston criteria (box 2). ${ }^{164}$ In the absence of direct neuropathological examination, CAA is diagnosed based on characteristic 
neuroimaging findings. ${ }^{164}$ The diagnosis of 'probable CAA' requires the following (box 2):

- Age $\geq 55$ years

- Detection of multiple haemorrhagic cerebral lesions

- Haemorrhages confined to cortical or cortical-subcortical (lobar) brain regions

- Exclusion of secondary causes of ICH, such as arteriovenous malformations, head trauma, brain tumour, vasculitis and excessive anticoagulation.

The specificity of the Boston criteria has been validated against the established gold standard of neuropathological diagnosis from autopsy, haematoma evacuation or cortical biopsy. ${ }^{164}$ In this study, the criteria showed excellent specificity: all cases identified as 'probable CAA' $(n=13)$ had pathological evidence of severe CAA. However, the sensitivity of the probable category was $44 \%$, so that it failed to identify over $50 \%$ of those with severe CAA pathology. ${ }^{164}$ However, this study does not

Box 2 Classic and modified Boston criteria for the diagnosis of cerebral amyloid angiopathy (CAA). ('Modifications compared with the classic Boston criteria based on Linn et al ${ }^{159}{ }^{164}$ )

\section{Definite CAA}

Full postmortem examination demonstrating:

- Lobar, cortical or cortical-subcortical haemorrhage

- Severe CAA with vasculopathy

- Absence of other diagnostic lesion

\section{Probable CAA with supporting pathology}

Clinical data and pathological tissue (evacuated haematoma or cortical biopsy) demonstrating:

- Lobar, cortical or cortical-subcortical haemorrhage

- Some degree of CAA in specimen

- Absence of other diagnostic lesion

\section{Probable CAA}

Clinical data and MRI or CT demonstrating:

- Multiple haemorrhages restricted to lobar, cortical or cortical-subcortical regions (cerebellar haemorrhage allowed)

* ${ }^{*}$ OR single lobar, cortical or cortical-subcortical haemorrhage and focal ${ }^{b}$ or disseminated ${ }^{c}$ superficial siderosis]

- Age $\geq 55$ years

- Absence of other cause of haemorrhage ${ }^{a}$

\section{Possible CAA}

Clinical data and MRI or CT demonstrating:

- Single lobar, cortical or cortical-subcortical haemorrhage

- ${ }^{*}\left[\mathrm{OR}\right.$ focal ${ }^{\mathrm{b}}$ or disseminated ${ }^{\mathrm{c}}$ superficial siderosis]

- Age $\geq 55$ years

- Absence of other cause of haemorrhage ${ }^{1}$

a Other causes of haemorrhage (differential diagnosis of lobar haemorrhages):

Antecedent head trauma

Haemorrhagic transformation of an ischaemic stroke

Arteriovenous malformation

Haemorrhagic tumour

Warfarin therapy with international normalisation ratio $>3$

Vasculitis

${ }^{\mathrm{b}}$ Focal siderosis: siderosis restricted to 3 or fewer sulci

'Disseminated siderosis: siderosis affecting at least 4 sulci reflect current radiological practice as only 15 patients had $\mathrm{T}^{*}$ GRE imaging. Recently, the application of the Boston criteria with a greater use of T2*-GRE MRI in Dutch-type hereditary CAA found a much improved sensitivity (especially when lobar CMBs were included in the criteria). ${ }^{165}$ The rationale for the inclusion of lobar CMBs in the criteria is that both lobar CMBs and lobar ICH represent independent vascular rupture events which are considered to offer equal evidence for the presence of CAA. ${ }^{166}$ The recently introduced SWI, a three-dimensional T2*-GRE technique, enables visualisation of CMBs with much increased sensitivity, resulting in higher lesion counts (at least $67 \%$ more compared with conventional T2*-GRE) (figure 4D), ${ }^{167-169}$ but its effect on diagnostic accuracy for CAA requires further study. Superficial siderosis and $\mathrm{CSAH}$, which have a high prevalence in CAA related ICH but are rare in other forms of ICH, have been shown to enhance the sensitivity of the Boston criteria without loss of specificity. ${ }^{159}$

Although the value of $\mathrm{T}^{*}$ weighted MRI and SWI in detecting CMBs, cSAH and siderosis has mainly been validated in cohorts of patients who presented with symptomatic ICH, such imaging may also have a role in the diagnosis of patients presenting without major haemorrhage but with other syndromes, raising suspicion of CAA; for example, elderly patients with progressive cognitive impairment. 118135168170171 In addition, although at present T2* MRI or SWI sequences are not part of the routine investigation of TIA-like attacks, there might be useful in patients with CAA related transient focal neurological episodes ('amyloid spells') - rather atypical of TIAs (figure 4G) ${ }^{132}{ }^{135}$ However, current data are insufficient to make evidence based recommendations.

Other biomarkers might also prove useful in the non-invasive diagnosis of $\mathrm{CAA}$, in particular the assessment of $\mathrm{A} \beta$ concentrations in CSF. Decreased levels of CSF $A \beta_{42}$ but not $A \beta_{40}$ are found in $A D^{172}$ while it has been reported that both $A \beta_{42}$ and $A \beta_{40}$ concentrations are decreased in CAA, relative to control and $\mathrm{AD}$ patients. ${ }^{173}$ It has also been suggested that the combination of low $A \beta_{42}$ with increased total $\tau$ levels in CSF, can discriminate CAA patients from normal controls with high accuracy. ${ }^{173}$ Another potentially promising marker of CAA might include retinal changes (microaneurysms and dot and blot haemorrhages ${ }^{174}$ ). A critical goal of all of these potential approaches is to reliably identify CAA at the early (asymptomatic) stages of the disease, to allow the best chance for disease modifying or preventive treatments to be effective.

\section{MANAGEMENT AND PROSPECTS FOR DISEASE MODIFICATION} Acute treatment

No treatment is specific for symptomatic management of CAA or CAA related ICH. As in all forms of spontaneous ICH, CAA related haematomas enlarge in the first few hours after onset, providing a potential target for treatment. One of the most promising available treatments in acute ICH is lowering blood pressure, which has been shown to reduce haematoma expansion in a randomised trial, ${ }^{175}$ presumably by reducing hydrostatic pressure into the ICH in the critical hyperacute phase; a further large study is underway. ${ }^{176}$ The role of neurosurgery in $\mathrm{ICH}$ remains to be defined clearly and is a topic of ongoing investigation. ${ }^{177}$ Although there have previously been concerns regarding surgery in CAA due to the risk of bleeding from fragile amyloid laden vessels, the available evidence does not suggest a particularly high operative risk. ${ }^{178-180}$ Neurosurgery for haematoma evacuation appears relatively safe in at least some patients with CAA related ICH, particularly in patients less than 75 years of age without intraventricular extension. ${ }^{180}$ Until 
further evidence of specific acute treatments is available, it is reasonable to follow the American Heart Association Stroke Council guidelines for acute management of $\mathrm{ICH}$, without modification for individuals with suspected CAA. ${ }^{181}$ Active research into new approaches for acute ICH treatment is expected to benefit patients with CAA related bleeds. Novel approaches, including neuroprotective drugs ${ }^{182} 183$ which target the multitude of processes that occur after ICH (eg, cerebral oedema, thrombin release, red blood cell lysis and haemoglobin induced neurotoxicity) ${ }^{184}$ and iron chelating agents (such as deferoxamine) ${ }^{185}$ are all being studied in early phase trials. ${ }^{9} 181186$

\section{Prevention of recurrent ICH}

Withholding anticoagulants and antiplatelets

It is a paradox that many elderly patients at highest risk of occlusive vascular events are also at the highest risk of haemorrhage complications, including ICH. Judging the balance of risk and benefit of antithrombotic treatment after ICH in those patients with an indication for vascular secondary prevention is thus a major clinical challenge. The available evidence on this topic is limited, consisting of generally small case control and prospective observational studies. In a recent prospective cohort of patients with spontaneous lobar ICH, an association was found between aspirin use and $\mathrm{ICH}$ recurrence after adjusting for other potential ICH risk factors (HR 3.95, $95 \%$ CI 1.6 to $8.3 ; \mathrm{p}<0.021) .{ }^{187}$ Rebleeding risk was associated with the number of lobar CMBs and the presence of leukoaraiosis in posterior brain regions-possible markers of underlying CAA and its severity. ${ }^{187}$ Gregoire et al in a small case control study found that lobar CMBs were associated with antiplatelet related $\mathrm{ICH}$, also supporting a link between CAA and antiplatelet related $\mathrm{ICH}^{188}$ Another small case control study of warfarin related ICH and matched ICH-free warfarin users showed an association of warfarin with CMBs, but with large CIs around the ORs for the association. ${ }^{189}$ There are no randomised trial data but a decision analysis suggested that in patients with CAA related $\mathrm{ICH}$, the use of anticoagulants to prevent future cardioembolic (atrial fibrillation related) stroke would lead to an $\mathrm{ICH}$ rate that outweighs any benefit from the treatment. ${ }^{190}$

Whether multiple lobar CMBs (without symptomatic ICH) confer an unacceptably high risk of future ICH with the use of antithrombotic agents requires further study. In a recent metaanalysis, Lovelock et al pooled the information of 1461 patients with ICH and 3817 patients with ischaemic stroke or TIAs and they showed that $\mathrm{CMBs}$ were more common in warfarin related ICH than 'spontaneous' ICH. In pooled follow-up data for 768 patients treated with antithrombotics (anticoagulant or antiplatelet drugs), the presence of $\mathrm{CMB}$ at baseline was associated with a significantly increased risk of future ICH (OR 12.1; 95\% CI 3.4 to $42.5 ; \mathrm{p}<0.001)$, but this study did not separately investigate the effects of lobar versus deep CMBs. ${ }^{191}$

For the moment, anticoagulation should usually be avoided in patients with a diagnosis of CAA and symptomatic lobar ICH, unless there is a very compelling need to treat that could outweigh the very high risk of recurrent $\mathrm{ICH}$ (eg, life threatening pulmonary embolism or a mechanical heart valve). Although antiplatelet drugs probably also increase future ICH risk in CAA, it may be reasonable to consider them in selected patients with CAA for secondary prevention in whom the risk of intracerebral bleeding is judged to be low and the risk of occlusive vascular events high, based on their clinical and imaging characteristics. In primary prevention, the risk/benefit ratio may favour withholding treatment in patients with multiple lobar
CMBs. Further randomised clinical trials are urgently needed to help clarify the optimum antithrombotic treatment in these different CAA patient groups.

\section{Blood pressure control}

A recent subgroup analysis of the PROGRESS trial reported that lowering blood pressure with the antihypertensive drug perindopril (with or without indapamide) reduced the risk of probable CAA related ICH by $77 \%$ (95\% CI $19 \%$ to $93 \%$ ) over a follow-up period of 3.9 years. ${ }^{38}$ Despite a small total number of CAA related ICH events, this is the first trial to show that blood pressure lowering treatment protects against CAA related $\mathrm{ICH}$, regardless of the presence of hypertension. ${ }^{38}$ Blood pressure lowering may also be associated with a more general benefit in cardiovascular risk and mortality in patients over the age of 80 years. ${ }^{192}$ Thus most patients with CAA and a history of symptomatic ICH should be offered antihypertensive treatment.

\section{Statins}

Recently, concerns have been raised over statins as a risk factor for ICH, in light of the results of the SPARCL trial of atorvastatin in patients with stroke, which showed a small increase in the incidence of $\mathrm{ICH}$ among patients receiving high doses of the drug $^{193}$; the hazard was higher for patients with baseline haemorrhagic compared with ischaemic stroke (HR 4.1 vs 1.6). ${ }^{194} \mathrm{~A}$ decision analysis showed that the risk of statin therapy likely outweighs any potential benefit in patients with recent lobar $\mathrm{ICH} .{ }^{195}$ Thus although there are inadequate data for clear recommendations on statin use, ${ }^{181}$ they should perhaps be avoided in the setting of a recent CAA related $\mathrm{ICH}^{196}$ For individuals with suspected CAA based on the presence of multiple lobar CMBs (without any associated macrobleeding) the risks and benefit of statin therapy are uncertain. ${ }^{11}$

\section{Disease modifying agents}

An important hope for the future treatment of CAA is to identify patients early in the natural history of the disease before ICH or dementia occurs, to allow the use of disease modifying therapies. ${ }^{197}$ Given the rarity of the inflammatory variant of CAA, it is unlikely that randomised data will become available to guide treatment, and it therefore seems reasonable to employ anti-inflammatory and immune modulating agents. ${ }^{197} 198$ However, future treatments for the great majority of sporadic CAA cases are likely to focus on preventing CAA progression by decreasing the production, deposition, toxicity and/or clearance of vascular amyloid. A candidate agent which might delay or inhibit the progression of CAA is tramiprosate, an ionic compound which binds soluble $A \beta$ and interferes with the amyloid cascade. ${ }^{199}$ Tramiprosate has been shown to be a safe treatment option for patients with suspected CAA in a phase 2 study, supporting future efficacy trials. ${ }^{200}$ Emerging data from the use of secretases inhibitors and/or immunisation against $A \beta$ in $\mathrm{AD}$ will be invaluable in guiding further efforts for disease modification in CAA.

\section{CONCLUSIONS}

During the past decade, there have been tremendous advancements in our understanding of CAA, relating to its pathophysiology, clinical spectrum, imaging manifestations and diagnosis.

- Sporadic CAA is a common disease of the elderly and will become an increasingly important healthcare challenge as populations age further. 
- Sporadic CAA is an important contributor to cognitive decline and spontaneous or anticoagulant related lobar $\mathrm{ICH}^{115}$

- Transient neurological spells in CAA may be misdiagnosed as TIAs, but seem to have characteristic clinical features; they need to be recognised as treating them with antithrombotic drugs may increase the risk of future ICH.

- Recent advances in neuroimaging have provided a new imaging window into the dynamic haemorrhagic and ischaemic features of CAA.

- Lobar CMBs, cSAH and cortical focal superficial siderosis show promise to reliably diagnose CAA in life, although validation of these findings against their histopathological correlates requires further study.

- Molecular imaging of $\mathrm{A} \beta$ may further improve our ability to detect this condition in vivo and define its true prevalence and burden. ${ }^{14-16} 141$

- The rapidly developing field of transgenic mouse modelling has provided significant insights into the pathophysiology of human CAA, including the key pathogenetic role of the perivascular drainage pathway and the differential effects of different ApoE genotypes. ${ }^{3}$

Despite our improved understanding of CAA, there are still many questions to be answered in order to identify targets for therapeutic and preventive interventions. Exciting diagnostic and therapeutic developments are on the horizon for this fascinating small vessel disorder.

Acknowledgements The authors thank Professor Sebastian Brander for providing some of the pathological images and Dr Estelle Healy for help in describing the histological slides. The authors are also most grateful to Dr Rolf $\mathrm{H}$ Jäger, Reader in Neuroradiology and Consultant Neuroradiologist at Queen Square, for assistance with MRI interpretation.

Funding $A C$ receives research support from the Greek State Scholarship Foundation. DJW receives research support from the Department of Health/Higher Education Funding Council for England (Clinical Senior Lectureship Award) and the Stroke Association. This work was undertaken at UCLH/UCL who received a proportion of funding from the Department of Health's NIHR Biomedical Research Centres funding scheme.

\section{Competing interests None.}

Contributors AC and DJW designed the draft paper. AC and QG performed the bibliographic search; DJW reviewed the literature included in the paper. All authors were involved in drafting the paper. DJW and AC revised the draft paper. AC designed the artwork with input and revisions by DJW.

Provenance and peer review Commissioned; externally peer reviewed.

\section{REFERENCES}

1. Brandner S. Histopathology of cerebral microbleeds. In: Werring DJ, ed. Cerebral microbleeds: pathophysiology to clinical practice. Cambridge: Cambridge University Press, 2011:49-64.

2. Vinters HV. Cerebral amyloid angiopathy. A critical review. Stroke 1987; 18:311-24

3. Attems J, Jellinger K, Thal DR, et al. Review: sporadic cerebral amyloid angiopathy. Neuropathol Appl Neurobiol 2011;37:75-93.

4. Oppenheim G. Über "drusige Nekrosen" in der Grosshirnrinde. Neurol Centralb/ 1909;28:410-13

5. Scholz W. Studienzurpathologiederhirngefabell: die drusige entartung der hirnarterien und capillaren. Gesamte Neurol Psychiatr 1938;162: 694-715.

6. Neumann MA. Combined amyloid vascular changes and argyrophilic plaques in the central nervous system. J Neuropathol Exp Neurol 1960;19:370-82.

7. Jellinger K. Cerebrovascular amyloidosis with cerebral hemorrhage. J Neurol 1977;214:195-206.

8. Okazaki H, Reagan TJ, Campbell RJ. Clinicopathologic studies of primary cerebral amyloid angiopathy. Mayo Clin Proc 1979;54:22-31.

9. Adeoye 0, Broderick JP. Advances in the management of intracerebral hemorrhage. Nat Rev Neurol 2010;6:593-601.

10. Qureshi Al, Mendelow AD, Hanley DF. Intracerebral haemorrhage. Lance 2009;373:1632-44
11. Charidimou A, Werring DJ. Cerebral microbleeds: detection, mechanisms and clinical challenges. Future Neurol 2011;6:587-611.

12. Kimberly WT, Gilson A, Rost NS, et al. Silent ischemic infarcts are associated with hemorrhage burden in cerebral amyloid angiopathy. Neurology 2009;72:1230-5.

13. Menon RS, Kidwell CS. Neuroimaging demonstration of evolving small vessel ischemic injury in cerebral amyloid angiopathy. Stroke 2009;40:e675-7.

14. Johnson KA, Gregas M, Becker JA, et al. Imaging of amyloid burden and distribution in cerebral amyloid angiopathy. Ann Neurol 2007:62:229-34.

15. Greenberg SM, Grabowski T, Gurol ME, et al. Detection of isolated cerebrovascular beta-amyloid with Pittsburgh compound B. Ann Neurol 2008;64:587-91.

16. Ly JV, Donnan GA, Villemagne VL, et al. 11C-PIB binding is increased in patients with cerebral amyloid angiopathy-related hemorrhage. Neurology 2010;74:487-93.

17. Jellinger KA. Alzheimer disease and cerebrovascular pathology: an update. J Neural Transm 2002:109:813-36.

18. Jellinger KA, Attems J. Incidence of cerebrovascular lesions in Alzheimer's disease: a postmortem study. Acta Neuropathol 2003:105:14-17.

19. Keage HA, Carare RO, Friedland RP, et al. Population studies of sporadic cerebral amyloid angiopathy and dementia: a systematic review. BMC Neurol 2009:9:3

20. Thal DR, Griffin WS, de Vos RA, et al. Cerebral amyloid angiopathy and its relationship to Alzheimer's disease. Acta Neuropathol 2008;115:599-609.

21. Xuereb JH, Brayne C, Dufouil C, et al. Neuropathological findings in the very old. Results from the first 101 brains of a population-based longitudinal study of dementing disorders. Ann N Y Acad Sci 2000;903:490-6.

22. Pathological correlates of late-onset dementia in a multicentre, community-based population in England and Wales. Neuropathology Group of the Medical Research Council Cognitive Function and Ageing Study (MRC CFAS). Lancet MRC CFAS 2001;357:169-75.

23. Pfeifer LA, White LR, Ross GW, et al. Cerebral amyloid angiopathy and cognitive function: the HAAS autopsy study. Neurology 2002;58:1629-34.

24. Tanskanen M, Lindsberg PJ, Tienari PJ, et al. Cerebral amyloid angiopathy in a 95 + cohort: complement activation and apolipoprotein E (ApoE) genotype. Neuropathol Appl Neurobiol 2005;31:589-99.

25. Kalaria RN, Ballard C. Overlap between pathology of Alzheimer disease and vascular dementia. Alzheimer Dis Assoc Disord 1999;13(Suppl 3):S115-23.

26. Ellis RJ, Olichney JM, Thal LJ, et al. Cerebral amyloid angiopathy in the brains of patients with Alzheimer's disease: the CERAD experience, Part XV. Neurology 1996:46:1592-6.

27. Mastaglia FL, Byrnes ML, Johnsen RD, et al. Prevalence of cerebral vascular amyloid-beta deposition and stroke in an aging Australian population: a postmortem study. J Clin Neurosci 2003;10:186-9.

28. Greenberg SM, Vonsattel JP. Diagnosis of cerebral amyloid angiopathy. Sensitivity and specificity of cortical biopsy. Stroke 1997;28:1418-22.

29. Lee SS, Stemmermann GN. Congophilic angiopathy and cerebral hemorrhage. Arch Pathol Lab Med 1978;102:317-21.

30. Itoh Y, Yamada M, Hayakawa M, et al. Cerebral amyloid angiopathy: a significant cause of cerebellar as well as lobar cerebral hemorrhage in the elderly. J Neurol Sci 1993; 116:135-41

31. Campbell DM, Bruins S, Vogel H, et al. Intracerebral hemorrhage caused by cerebral amyloid angiopathy in a 53-year-old man. J Neurol 2008;255:597-8.

32. Pantoni L. Cerebral small vessel disease: from pathogenesis and clinical characteristics to therapeutic challenges. Lancet Neurol 2010;9:689-701.

33. Lloyd-Jones DM, Evans JC, Levy D. Hypertension in adults across the age spectrum: current outcomes and control in the community. JAMA 2005:294:466-72

34. Vonsattel JP, Myers RH, Hedley-Whyte ET, et al. Cerebral amyloid angiopathy without and with cerebral hemorrhages: a comparative histological study. Ann Neurol 1991;30:637-49.

35. Gregoire SM, Charidimou A, Gadapa N, et al. Acute ischaemic brain lesions in intracerebral haemorrhage: multicentre cross-sectional magnetic resonance imaging study. Brain 2011;134:2376-86.

36. Ferreiro JA, Ansbacher LE, Vinters HV. Stroke related to cerebral amyloid angiopathy: the significance of systemic vascular disease. J Neurol 1989;236:267-72.

37. Broderick J, Brott T, Tomsick T, et al. Lobar hemorrhage in the elderly. The undiminishing importance of hypertension. Stroke 1993;24:49-51.

38. Arima H, Tzourio C, Anderson C, et al. Effects of perindopril-based lowering of blood pressure on intracerebral hemorrhage related to amyloid angiopathy: the PROGRESS trial. Stroke 2010;41:394-6.

39. Verghese PB, Castellano JM, Holtzman DM. Apolipoprotein E in Alzheimer's disease and other neurological disorders. Lancet Neurol 2011;10:241-52.

40. Zannis VI, Breslow JL, Utermann G, et al. Proposed nomenclature of apoE isoproteins, apoE genotypes, and phenotypes. J Lipid Res 1982;23:911-14.

41. Mahley RW, Rall SC Jr. Apolipoprotein E: far more than a lipid transport protein Annu Rev Genomics Hum Genet 2000;1:507-37.

42. Greenberg SM, Rebeck GW, Vonsattel JP, et al. Apolipoprotein E epsilon 4 and cerebral hemorrhage associated with amyloid angiopathy. Ann Neurol 1995;38:254-9.

43. Premkumar DR, Cohen DL, Hedera P, et al. Apolipoprotein E-epsilon4 alleles in cerebral amyloid angiopathy and cerebrovascular pathology associated with Alzheimer's disease. Am J Pathol 1996;148:2083-95. 
44. Biffi A, Sonni A, Anderson CD, et al. Variants at APOE influence risk of deep and lobar intracerebral hemorrhage. Ann Neurol 2010;68:934-43.

45. Nicoll JA, Burnett C, Love S, et al. High frequency of apolipoprotein E epsilon 2 allele in hemorrhage due to cerebral amyloid angiopathy. Ann Neurol 1997:41:716-21.

46. Greenberg SM, Briggs ME, Hyman BT, et al. Apolipoprotein E epsilon 4 is associated with the presence and earlier onset of hemorrhage in cerebral amyloid angiopathy. Stroke 1996;27:1333-7.

47. Biffi A, Anderson CD, Jagiella JM, et al. APOE genotype and extent of bleeding and outcome in lobar intracerebral haemorrhage: a genetic association study. Lancet Neurol 2011;10:702-9.

48. Montaner J. Genetics of intracerebral haemorrhage: a tsunami effect of APOE varepsilon2 genotype on brain bleeding size? Lancet Neurol 2011;10:673-5.

49. O'Donnell HC, Rosand J, Knudsen KA, et al. Apolipoprotein E genotype and the risk of recurrent lobar intracerebral hemorrhage. $N$ Engl J Med 2000;342:240-5.

50. Greenberg SM, Vonsattel JP, Segal AZ, et al. Association of apolipoprotein E epsilon2 and vasculopathy in cerebral amyloid angiopathy. Neurology 1998; $\mathbf{5 0}: 961-5$.

51. McCarron MO, Nicoll JA, Stewart J, et al. The apolipoprotein E epsilon2 allele and the pathological features in cerebral amyloid angiopathy-related hemorrhage. $J$ Neuropathol Exp Neurol 1999;58:711-18.

52. Walker LC, Pahnke J, Madauss M, et al. Apolipoprotein E4 promotes the early deposition of Abeta42 and then Abeta40 in the elderly. Acta Neuropathol 2000:100:36-42

53. Fryer JD, Simmons K, Parsadanian M, et al. Human apolipoprotein E4 alters the amyloid-beta 40:42 ratio and promotes the formation of cerebral amyloid angiopathy in an amyloid precursor protein transgenic model. J Neurosci 2005;25:2803-10.

54. Herzig MC, Van Nostrand WE, Jucker M. Mechanism of cerebral beta-amyloid angiopathy: murine and cellular models. Brain Pathol 2006:16:40-54.

55. Davis J, Xu F, Deane R, et al. Early-onset and robust cerebral microvascular accumulation of amyloid beta-protein in transgenic mice expressing low levels of a vasculotropic Dutch/lowa mutant form of amyloid beta-protein precursor. J Biol Chem 2004;279:20296-306.

56. Preston SD, Steart PV, Wilkinson A, et al. Capillary and arterial cerebral amyloid angiopathy in Alzheimer's disease: defining the perivascular route for the elimination of amyloid beta from the human brain. Neuropathol Appl Neurobiol 2003:29:106-17.

57. Yamada M, Sodeyama N, Itoh $\mathrm{Y}$, et al. Association of presenilin-1 polymorphism with cerebral amyloid angiopathy in the elderly. Stroke 1997;28:2219-21.

58. Yamada M. Cerebral amyloid angiopathy and gene polymorphisms. J Neurol Sci 2004;226:41-4.

59. Hamaguchi T, Okino S, Sodeyama $\mathrm{N}$, et al. Association of a polymorphism of the transforming growth factor-beta1 gene with cerebral amyloid angiopathy. J Neurol Neurosurg Psychiatry 2005;76:696-9.

60. Glenner GG, Wong CW. Alzheimer's disease: initial report of the purification and characterization of a novel cerebrovascular amyloid protein. Biochem Biophys Res Commun 1984;120:885-90.

61. Roher AE, Lowenson JD, Clarke S, et al. beta-Amyloid-(1-42) is a major component of cerebrovascular amyloid deposits: implications for the pathology of Alzheimer disease. Proc Natl Acad Sci U S A 1993;90:10836-40.

62. Gravina SA, Ho L, Eckman CB, et al. Amyloid beta protein (A beta) in Alzheimer's disease brain. Biochemical and immunocytochemical analysis with antibodies specific for forms ending at A beta 40 or A beta 42(43). J Biol Chem 1995:270:7013-16

63. Attems J, Lintner F, Jellinger KA. Amyloid beta peptide 1-42 highly correlates with capillary cerebral amyloid angiopathy and Alzheimer disease pathology. Acta Neuropathol 2004;107:283-91

64. Revesz T, Holton JL, Lashley T, et al. Genetics and molecular pathogenesis of sporadic and hereditary cerebral amyloid angiopathies. Acta Neuropathol 2009;118:115-30.

65. Puchtler $\mathbf{H}$, Waldrop FS, Meloan SN. A review of light, polarization and fluorescence microscopic methods for amyloid. Appl Pathol 1985;3:5-17.

66. Revesz T, Holton JL, Lashley T, et al. Sporadic and familial cerebral amyloid angiopathies. Brain Pathol 2002;12:343-57.

67. Olichney JM, Hansen LA, Hofstetter CR, et al. Cerebral infarction in Alzheimer's disease is associated with severe amyloid angiopathy and hypertension. Arch Neurol 1995; 52:702-8.

68. Cadavid $\mathbf{D}$, Mena $\mathrm{H}$, Koeller $\mathrm{K}$, et al. Cerebral beta amyloid angiopathy is a risk factor for cerebral ischemic infarction. A case control study in human brain biopsies. J Neuropathol Exp Neurol 2000:59:768-73.

69. Haglund M, Passant U, Sjobeck M, et al. Cerebral amyloid angiopathy and cortical microinfarcts as putative substrates of vascular dementia. Int J Geriatr Psychiatry 2006;21:681-7.

70. Thal DR, Ghebremedhin E, Orantes M, et al. Vascular pathology in Alzheimer disease: correlation of cerebral amyloid angiopathy and arteriosclerosis/ lipohyalinosis with cognitive decline. J Neuropathol Exp Neurol 2003;62:1287-301.

71. Attems J. Sporadic cerebral amyloid angiopathy: pathology, clinical implications, and possible pathomechanisms. Acta Neuropathol 2005:110:345-59.

72. Greenberg SM, Gurol ME, Rosand J, et al. Amyloid angiopathy-related vascular cognitive impairment. Stroke 2004;35:2616-19.
73. Thal DR, Ghebremedhin E, Rub U, et al. Two types of sporadic cerebral amyloid angiopathy. J Neuropathol Exp Neurol 2002;61:282-93.

74. Thal DR, Papassotiropoulos A, Saido TC, et al. Capillary cerebral amyloid angiopathy identifies a distinct APOE epsilon4-associated subtype of sporadic Alzheimer's disease. Acta Neuropathol 2010;120:169-83.

75. Vinters HV, Gilbert JJ. Cerebral amyloid angiopathy: incidence and complications in the aging brain. II. The distribution of amyloid vascular changes. Stroke 1983; 14:924-8

76. Attems $\mathrm{J}$, Quass $\mathrm{M}$, Jellinger $\mathrm{KA}$, et al. Topographical distribution of cerebral amyloid angiopathy and its effect on cognitive decline are influenced by Alzheimer disease pathology. J Neurol Sci 2007;257:49-55.

77. Biffi A, Greenberg SM. Cerebral amyloid angiopathy: a systematic review. J Clin Neurol 2011;7:1-9.

78. Mead S, James-Galton M, Revesz $\mathrm{T}$, et al. Familial British dementia with amyloid angiopathy: early clinical, neuropsychological and imaging findings. Brain 2000;123:975-91

79. Vidal R, Frangione B, Rostagno A, et al. A stop-codon mutation in the BRI gene associated with familial British dementia. Nature 1999:399:776-81

80. Vidal R, Revesz T, Rostagno A, et al. A decamer duplication in the $3^{\prime}$ region of the $\mathrm{BRI}$ gene originates an amyloid peptide that is associated with dementia in a Danish kindred. Proc Natl Acad Sci U S A 2000;97:4920-5.

81. Palsdottir A, Abrahamson M, Thorsteinsson L, et al. Mutation in cystatin $C$ gene causes hereditary brain haemorrhage. Lancet 1988;2:603-4.

82. Revesz T, Ghiso J, Lashley T, et al. Cerebral amyloid angiopathies: a pathologic, biochemical, and genetic view. J Neuropathol Exp Neurol 2003;62:885-98.

83. Melchor JP, McVoy L, Van Nostrand WE. Charge alterations of E22 enhance the pathogenic properties of the amyloid beta-protein. $J$ Neurochem 2000:74:2209-12.

84. Van Nostrand WE, Melchor JP, Cho HS, et al. Pathogenic effects of D23N lowa mutant amyloid beta-protein. J Biol Chem 2001;276:32860-6.

85. Van Nostrand WE, Melchor JP, Romanov G, et al. Pathogenic effects of cerebral amyloid angiopathy mutations in the amyloid beta-protein precursor. Ann N Y Acad Sci 2002:977:258-65.

86. Tsubuki S, Takaki Y, Saido TC. Dutch, Flemish, Italian, and Arctic mutations of APP and resistance of Abeta to physiologically relevant proteolytic degradation. Lancet 2003; 361:1957-8.

87. Love S, Miners S, Palmer J, et al. Insights into the pathogenesis and pathogenicity of cerebral amyloid angiopathy. Front Biosci 2009;14:4778-92.

88. Burgermeister P, Calhoun ME, Winkler DT, et al. Mechanisms of cerebrovascular amyloid deposition. Lessons from mouse models. Ann N Y Acad Sci 2000;903:307-16.

89. Bu G. Apolipoprotein $E$ and its receptors in Alzheimer's disease: pathways, pathogenesis and therapy. Nat Rev Neurosci 2009;10:333-44.

90. Weller RO, Nicoll JA. Cerebral amyloid angiopathy: both viper and maggot in the brain. Ann Neurol 2005:58:348-50.

91. Weller RO, Djuanda E, Yow HY, et al. Lymphatic drainage of the brain and the pathophysiology of neurological disease. Acta Neuropathol 2009;117:1-14.

92. Schley D, Carare-Nnadi R, Please CP, et al. Mechanisms to explain the reverse perivascular transport of solutes out of the brain. J Theor Biol 2006;238:962-74.

93. Weller RO, Yow HY, Preston SD, et al. Cerebrovascular disease is a major factor in the failure of elimination of Abeta from the aging human brain: implications for therapy of Alzheimer's disease. Ann N Y Acad Sci 2002;977:162-8.

94. Roher AE, Kuo YM, Esh C, et al. Cortical and leptomeningeal cerebrovascular amyloid and white matter pathology in Alzheimer's disease. Mol Med 2003;9:112-22.

95. Wardlaw JM. Blood-brain barrier and cerebral small vessel disease. J Neurol Sci 2010;299:66-71.

96. Doubal FN, MacLullich AM, Ferguson KJ, et al. Enlarged perivascular spaces on MRI are a feature of cerebral small vessel disease. Stroke 2010:41:450-4.

97. Thal DR, Larionov S, Abramowski D, et al. Occurrence and co-localization of amyloid beta-protein and apolipoprotein $\mathrm{E}$ in perivascular drainage channels of wildtype and APP-transgenic mice. Neurobiol Aging 2007;28:1221-30.

98. Jack CR Jr, Knopman DS, Jagust WJ, et al. Hypothetical model of dynamic biomarkers of the Alzheimer's pathological cascade. Lancet Neurol 2010:9:119-28.

99. Smith EE, Greenberg SM. Beta-amyloid, blood vessels, and brain function. Stroke 2009:40:2601-6.

100. Dotti CG, De Strooper B. Alzheimer's dementia by circulation disorders: when trees hide the forest. Nat Cell Biol 2009;11:114-16.

101. Iadecola C. Neurovascular regulation in the normal brain and in Alzheimer's disease. Nat Rev Neurosci 2004;5:347-60.

102. Rosenberg GA. Inflammation and white matter damage in vascular cognitive impairment. Stroke 2009:40:S20-3.

103. Rosenberg GA, Sullivan N, Esiri MM. White matter damage is associated with matrix metalloproteinases in vascular dementia. Stroke 2001;32:1162-8.

104. Rosand J, Muzikansky A, Kumar A, et al. Spatial clustering of hemorrhages in probable cerebral amyloid angiopathy. Ann Neurol 2005;58:459-62.

105. Pezzini A, Padovani A. Cerebral amyloid angiopathy-related hemorrhages. Neurol Sci 2008;29(Suppl 2):S260-3.

106. Pezzini A, Del Zotto E, Volonghi I, et al. Cerebral amyloid angiopathy: a common cause of cerebral hemorrhage. Curr Med Chem 2009;16:2498-513.

107. Olichney JM, Hansen LA, Hofstetter CR, et al. Association between severe cerebral amyloid angiopathy and cerebrovascular lesions in Alzheimer disease 
is not a spurious one attributable to apolipoprotein E4. Arch Neurol 2000;57:869-74

108. Ritter MA, Droste DW, Hegedus K, et al. Role of cerebral amyloid angiopathy in intracerebral hemorrhage in hypertensive patients. Neurology 2005;64:1233-7.

109. Jellinger KA, Lauda F, Attems J. Sporadic cerebral amyloid angiopathy is not a frequent cause of spontaneous brain hemorrhage. Eur J Neurol 2007;14:923-8.

110. Attems J, Lauda F, Jellinger KA. Unexpectedly low prevalence of intracerebral hemorrhages in sporadic cerebral amyloid angiopathy: an autopsy study. J Neurol 2008:255:70-6.

111. Yamada M, Itoh $\mathrm{Y}$, Otomo $\mathrm{E}$, et al. Subarachnoid haemorrhage in the elderly: a necropsy study of the association with cerebral amyloid angiopathy. $J$ Neurol Neurosurg Psychiatry 1993;56:543-7.

112. Passero S, Burgalassi L, D'Andrea P, et al. Recurrence of bleeding in patients with primary intracerebral hemorrhage. Stroke 1995;26:1189-92.

113. Flibotte JJ, Hagan N, O'Donnell J, et al. Warfarin, hematoma expansion, and outcome of intracerebral hemorrhage. Neurology 2004;63:1059-64.

114. Flaherty ML, Kissela B, Woo D, et al. The increasing incidence of anticoagulantassociated intracerebral hemorrhage. Neurology 2007;68:116-21.

115. Rosand J, Hylek EM, O'Donnell HC, et al. Warfarin-associated hemorrhage and cerebral amyloid angiopathy: a genetic and pathologic study. Neurology 2000;55:947-51.

116. McCarron MO, Nicoll JA. Cerebral amyloid angiopathy and thrombolysis-related intracerebral haemorrhage. Lancet Neurol 2004:3:484-92.

117. Sloan MA, Price TR, Petito CK, et al. Clinical features and pathogenesis of intracerebral hemorrhage after rt-PA and heparin therapy for acute myocardia infarction: the Thrombolysis in Myocardial Infarction (TIMI) II Pilot and Randomized Clinical Trial combined experience. Neurology 1995;45:649-58.

118. Gorelick PB, Scuteri A, Black SE, et al. Vascular contributions to cognitive impairment and dementia: a statement for healthcare professionals from the American Heart Association/American Stroke Association. Stroke 2011;:42:2672-713

119. Arvanitakis Z, Leurgans SE, Wang Z, et al. Cerebral amyloid angiopathy pathology and cognitive domains in older persons. Ann Neurol 2011:69:320-7.

120. Werring DJ, Gregoire SM, Cipolotti L. Cerebral microbleeds and vascular cognitive impairment. J Neurol Sci 2010;299:131-5.

121. Soontornniyomkij V, Lynch MD, Mermash S, et al. Cerebral microinfarcts associated with severe cerebral beta-amyloid angiopathy. Brain Pathol 2010;20:459-67.

122. Holland CM, Smith EE, Csapo I, et al. Spatial distribution of white-matter hyperintensities in Alzheimer disease, cerebral amyloid angiopathy, and healthy aging. Stroke 2008;39:1127-33.

123. Iadecola $\mathbf{C}$. The overlap between neurodegenerative and vascular factors in the pathogenesis of dementia. Acta Neuropathol 2010;120:287-96.

124. Hachinski V. Shifts in thinking about dementia. JAMA 2008;300:2172-3.

125. Fotuhi M, Hachinski V, Whitehouse PJ. Changing perspectives regarding late-life dementia. Nat Rev Neurol 2009;5:649-58.

126. Chung KK, Anderson NE, Hutchinson D, et al. Cerebral amyloid angiopathy related inflammation: three case reports and a review. J Neurol Neurosurg Psychiatry 2011;82:20-6

127. Wildemann B, Jarius $\mathrm{S}$, Hartmann $\mathrm{M}$, et al. Acute disseminated encephalomyelitis following vaccination against human papilloma virus. Neurology 2009;72:2132-3.

128. Kinnecom C, Lev MH, Wendell L, et al. Course of cerebral amyloid angiopathyrelated inflammation. Neurology 2007:68:1411-16.

129. Nicoll JA, Wilkinson D, Holmes C, et al. Neuropathology of human Alzheimer disease after immunization with amyloid-beta peptide: a case report. Nat Med 2003; 9:448-52.

130. Ferrer I, Boada Rovira M, Sanchez Guerra ML, et al. Neuropathology and pathogenesis of encephalitis following amyloid-beta immunization in Alzheimer's disease. Brain Pathol 2004;14:11-20.

131. Greenberg SM, Vonsattel JP, Stakes JW, et al. The clinical spectrum of cerebral amyloid angiopathy: presentations without lobar hemorrhage. Neurology 1993; 43:2073-9

132. Roch JA, Nighoghossian N, Hermier M, et al. Transient neurologic symptoms related to cerebral amyloid angiopathy: usefulness of $\mathrm{T} 2^{*}$-weighted imaging. Cerebrovasc Dis 2005;20:412-14.

133. Smith DB, Hitchcock M, Philpott PJ. Cerebral amyloid angiopathy presenting as transient ischemic attacks. Case report. J Neurosurg 1985;63:963-4.

134. Finelli PF. Cerebral amyloid angiopathy as cause of convexity SAH in elderly. Neurologist 2010;16:37-40.

135. Raposo N, Viguier A, Cuvinciuc V, et al. Cortical subarachnoid haemorrhage in the elderly: a recurrent event probably related to cerebral amyloid angiopathy. Eur J Neurol 2011:18:597-603.

136. Greenberg SM, Vernooij MW, Cordonnier C, et al. Cerebral microbleeds: a guide to detection and interpretation. Lancet Neurol 2009;8:165-74.

137. Fazekas F, Kleinert R, Roob G, et al. Histopathologic analysis of foci of signal loss on gradient-echo $\mathrm{T} 2{ }^{*}$-weighted MR images in patients with spontaneous intracerebral hemorrhage: evidence of microangiopathy-related microbleeds. AJNR Am J Neuroradiol 1999;20:637-42.

138. Schrag M, McAuley G, Pomakian J, et al. Correlation of hypointensities in susceptibility-weighted images to tissue histology in dementia patients with cerebral amyloid angiopathy: a postmortem MRI study. Acta Neuropathol 2010;119:291-302.
139. Poels MM, Vernooij MW, Ikram MA, et al. Prevalence and risk factors of cerebral microbleeds: an update of the Rotterdam scan study. Stroke 2010;41: S103-6.

140. Vernooij MW, van der Lugt A, Ikram MA, et al. Prevalence and risk factors of cerebral microbleeds: the Rotterdam Scan Study. Neurology 2008;70:1208-14.

141. Dierksen GA, Skehan ME, Khan MA, et al. Spatial relation between microbleeds and amyloid deposits in amyloid angiopathy. Ann Neurol 2010;68:545-8.

142. Greenberg SM, Eng JA, Ning M, et al. Hemorrhage burden predicts recurrent intracerebral hemorrhage after lobar hemorrhage. Stroke 2004;35:1415-20.

143. Jeerakathil T, Wolf PA, Beiser A, et al. Cerebral microbleeds: prevalence and associations with cardiovascular risk factors in the Framingham Study. Stroke 2004;35:1831-5.

144. Sveinbjornsdottir S, Sigurdsson S, Aspelund T, et al. Cerebral microbleeds in the population based AGES-Reykjavik study: prevalence and location. J Neurol Neurosurg Psychiatry 2008;79:1002-6.

145. Cordonnier C, van der Flier WM. Brain microbleeds and Alzheimer's disease: innocent observation or key player? Brain 2011;134:335-44

146. Ryan NS, Bastos-Leite AJ, Rohrer JD, et al. Cerebral microbleeds in familial Alzheimer's disease. Brain. Published Online First: 17 June 2011. doi:awr126 [pii] 10.1093/brain/awr126.

147. Debette S, Markus HS. The clinical importance of white matter hyperintensities on brain magnetic resonance imaging: systematic review and meta-analysis. BMJ 2010;341:c3666.

148. Gouw AA, Seewann A, van der Flier WM, et al. Heterogeneity of small vessel disease: a systematic review of MRI and histopathology correlations. J Neurol Neurosurg Psychiatry 2010;82:126-35

149. Potter GM, Doubal FN, Jackson CA, et al. Counting cavitating lacunes underestimates the burden of lacunar infarction. Stroke 2010;41:267-72.

150. Smith EE. Leukoaraiosis and stroke. Stroke 2010;41:S139-43.

151. Zhu YC, Chabriat H, Godin 0, et al. Distribution of white matter hyperintensity in cerebral hemorrhage and healthy aging. J Neurol. Published Online First: 30 August 2011. doi:10.1007/s00415-011-6218-3.

152. Smith EE, Gurol ME, Eng JA, et al. White matter lesions, cognition, and recurrent hemorrhage in lobar intracerebral hemorrhage. Neurology 2004;63:1606-12.

153. Chen YW, Gurol ME, Rosand J, et al. Progression of white matter lesions and hemorrhages in cerebral amyloid angiopathy. Neurology 2006;67:83-7.

154. Linn J, Herms J, Dichgans M, et al. Subarachnoid hemosiderosis and superficial cortical hemosiderosis in cerebral amyloid angiopathy. AJNR Am J Neuroradiol 2008;29:184-6

155. Kumar S, Goddeau RP Jr, Selim MH, et al. Atraumatic convexal subarachnoid hemorrhage: clinical presentation, imaging patterns, and etiologies. Neurology 2010;74:893-9

156. Cuvinciuc V, Viguier A, Calviere L, et al. Isolated acute nontraumatic cortical subarachnoid hemorrhage. AJNR Am J Neuroradiol 2010;31:1355-62.

157. Kase CS, Nguyen TN. The clinical conundrum of convexal subarachnoid hemorrhage. Neurology 2010;74:874-5.

158. Beitzke M, Gattringer T, Enzinger $\mathrm{C}$, et al. Clinical presentation, etiology, and longterm prognosis in patients with nontraumatic convexal subarachnoid hemorrhage. Stroke 2011:42:3055-60.

159. Linn J, Halpin A, Demaerel $P$, et al. Prevalence of superficial siderosis in patients with cerebral amyloid angiopathy. Neurology 2010;74:1346-50.

160. Kumar N, Cohen-Gadol AA, Wright RA, et al. Superficial siderosis. Neurology 2006;66:1144-52

161. Kidwell CS, Greenberg SM. Red meets white: do microbleeds link hemorrhagic and ischemic cerebrovascular disease? Neurology 2009;73:1614-15.

162. Nordberg A, Rinne JO, Kadir A, et al. The use of PET in Alzheimer disease. Nat Rev Neurol 2010;6:78-87.

163. Bacskai BJ, Frosch MP, Freeman SH, et al. Molecular imaging with Pittsburgh Compound B confirmed at autopsy: a case report. Arch Neurol 2007;64:431-4.

164. Knudsen KA, Rosand J, Karluk D, et al. Clinical diagnosis of cerebral amyloid angiopathy: validation of the Boston criteria. Neurology 2001;56:537-9.

165. van Rooden S, van der Grond J, van den Boom R, et al. Descriptive analysis of the Boston criteria applied to a Dutch-type cerebral amyloid angiopathy population. Stroke 2009; 40:3022-7.

166. Khan MA, Viswanathan A, Greenberg MS. Cerebral microbleeds in relation to cerebral amyloid angiopathy. In: Werring DJ, ed. Cerebral microbleeds. pathophysiology to clinical practice. Cambridge: Cambridge University Press, 2011:109-16.

167. Mittal S, Wu Z, Neelavalli J, et al. Susceptibility-weighted imaging: technical aspects and clinical applications, part 2. AJNR Am J Neuroradiol 2009;30:232-52

168. Ayaz M, Boikov AS, Haacke EM, et al. Imaging cerebral microbleeds using susceptibility weighted imaging: one step toward detecting vascular dementia. J Magn Reson Imaging 2010;31:142-8.

169. Nandigam RN, Viswanathan A, Delgado P, et al. MR imaging detection of cerebra microbleeds: effect of susceptibility-weighted imaging, section thickness, and field strength. AJNR Am J Neuroradiol 2009;30:338-43.

170. Chao CP, Kotsenas AL, Broderick DF. Cerebral amyloid angiopathy: CT and MR imaging findings. Radiographics 2006;26:1517-31.

171. Walker DA, Broderick DF, Kotsenas AL, et al. Routine use of gradient-echo MRI to screen for cerebral amyloid angiopathy in elderly patients. AJR Am J Roentgenol 2004;182:1547-50. 
172. de Jong D, Kremer BP, Olde Rikkert MG, et al. Current state and future directions of neurochemical biomarkers for Alzheimer's disease. Clin Chem Lab Med 2007; 45:1421-34.

173. Verbeek MM, Kremer BP, Rikkert MO, et al. Cerebrospinal fluid amyloid beta(40) is decreased in cerebral amyloid angiopathy. Ann Neurol 2009;66:245-9.

174. Lee A, Rudkin A, Agzarian M, et al. Retinal vascular abnormalities in patients with cerebral amyloid angiopathy. Cerebrovasc Dis 2009;28:618-22.

175. Anderson CS, Huang Y, Wang JG, et al. Intensive blood pressure reduction in acute cerebral haemorrhage trial (INTERACT): a randomised pilot trial. Lancet Neurol 2008:7:391-9

176. Delcourt C, Huang Y, Wang J, et al. The second (main) phase of an open, randomised, multicentre study to investigate the effectiveness of an intensive blood pressure reduction in acute cerebral haemorrhage trial (INTERACT2). Int J Stroke 2010;5:110-16.

177. Mendelow AD, Gregson BA, Mitchell PM, et al. Surgical trial in lobar intracerebral haemorrhage (STICH II) protocol. Trials 2011;12:124.

178. Greene GM, Godersky JC, Biller J, et al. Surgical experience with cerebral amyloid angiopathy. Stroke 1990;21:1545-9.

179. Leblanc R, Preul M, Robitaille Y, et al. Surgical considerations in cerebral amyloid angiopathy. Neurosurgery 1991;29:712-18.

180. Izumihara A, Ishihara T, Iwamoto $\mathbf{N}$, et al. Postoperative outcome of 37 patients with lobar intracerebral hemorrhage related to cerebral amyloid angiopathy. Stroke 1999;30:29-33.

181. Morgenstern LB, Hemphill JC 3rd, Anderson C, et al. Guidelines for the management of spontaneous intracerebral hemorrhage: a guideline for healthcare professionals from the American Heart Association/American Stroke Association. Stroke 2010;41:2108-29.

182. Lyden PD, Shuaib A, Lees KR, et al. Safety and tolerability of NXY-059 for acute intracerebral hemorrhage: the CHANT Trial. Stroke 2007;38:2262-9.

183. Haley EC Jr, Thompson JL, Levin B, et al. Gavestinel does not improve outcome after acute intracerebral hemorrhage: an analysis from the GAIN International and GAIN Americas studies. Stroke 2005;36:1006-10.

184. Xi G, Keep RF, Hoff JT. Mechanisms of brain injury after intracerebral haemorrhage. Lancet Neurol 2006:5:53-63.

185. Selim M. Deferoxamine mesylate: a new hope for intracerebral hemorrhage: from bench to clinical trials. Stroke 2009:40:S90-1.
186. Kellner CP, Connolly ES Jr. Neuroprotective strategies for intracerebral hemorrhage: trials and translation. Stroke 2010;41:S99-102.

187. Biffi A, Halpin A, Towfighi A, et al. Aspirin and recurrent intracerebral hemorrhage in cerebral amyloid angiopathy. Neurology 2010;75:693-8.

188. Gregoire SM, Jager HR, Yousry TA, et al. Brain microbleeds as a potential risk factor for antiplatelet-related intracerebral haemorrhage: hospital-based, casecontrol study. J Neurol Neurosurg Psychiatry 2010;81:679-84.

189. Lee SH, Ryu WS, Roh JK. Cerebral microbleeds are a risk factor for warfarin-related intracerebral hemorrhage. Neurology 2009:72:171-6.

190. Eckman MH, Wong LK, Soo YO, et al. Patient-specific decision-making for warfarin therapy in nonvalvular atrial fibrillation: how will screening with genetics and imaging help? Stroke 2008;39:3308-15.

191. Lovelock CE, Cordonnier C, Naka H, et al. Antithrombotic drug use, cerebra microbleeds, and intracerebral hemorrhage: a systematic review of published and unpublished studies. Stroke 2010;41:1222-8.

192. Bulpitt CJ, Beckett NS, Peters R, et al. Blood pressure control in the Hypertension in the Very Elderly Trial (HYVET). J Hum Hypertens. Published Online First: 10 March 2011. jhh201110 [pii] 10.1038/jhh.2011.10.

193. Amarenco P, Bogousslavsky J, Callahan A 3rd, et al. High-dose atorvastatin after stroke or transient ischemic attack. N Engl J Med 2006:355:549-59.

194. Goldstein LB, Amarenco P, Szarek M, et al. Hemorrhagic stroke in the Stroke Prevention by Aggressive Reduction in Cholesterol Levels study. Neurology 2008:70:2364-70.

195. Westover MB, Bianchi MT, Eckman MH, et al. Statin use following intracerebra hemorrhage: a decision analysis. Arch Neurol 2011;68:573-9.

196. Goldstein LB. Statins after intracerebral hemorrhage: to treat or not to treat. Arch Neurol 2011;:68:565-6

197. Kloppenborg RP, Richard E, Sprengers ME, et al. Steroid responsive encephalopathy in cerebral amyloid angiopathy: a case report and review of evidence for immunosuppressive treatment. J Neuroinflammation 2010; 7:18.

198. Luppe S, Betmouni S, Scolding N, et al. Cerebral amyloid angiopathy related vasculitis: successful treatment with azathioprine. J Neurol 2010;257:2103-5.

199. Gervais F, Paquette J, Morissette C, et al. Targeting soluble Abeta peptide with tramiprosate for the treatment of brain amyloidosis. Neurobiol Aging 2007:28:537-47.

200. Greenberg SM, Rosand J, Schneider AT, et al. A phase 2 study of tramiprosate for cerebral amyloid angiopathy. Alzheimer Dis Assoc Disord 2006:20:269-74. 